Check for updates

Cite this: RSC Adv., 2018, 8, 8856

\title{
The nano heat effect of replacing macro-particles by nano-particles in drop calorimetry: the case of core/shell metal/oxide nano-particles
}

\author{
A. Yakymovych, (D)*ab G. Kaptay, iD cde H. Flandorfer, ${ }^{a}$ J. Bernardi, ${ }^{f}$ S. Schwarz ${ }^{f}$ \\ and H. Ipser ${ }^{a}$
}

Experimental results are presented here obtained by a drop calorimetric method, in which $\mathrm{Ni}$ and $\mathrm{Cu}$ particles, both in bulk and nanosized form, were dropped into a liquid Sn-3.8Ag-0.7Cu solder alloy (in wt\%). The molar enthalpies of mixing of the liquid ( $\mathrm{Sn}-3.8 \mathrm{Ag}-0.7 \mathrm{Cu})-\mathrm{Ni}(\mathrm{Cu})$ alloys were measured. An extra exothermic heat effect is observed when dropping nano-particles instead of macro-particles. This is partly due to the loss of the large surface area and the corresponding large surface enthalpy of the nano-particles before their dissolution in the liquid alloy. However, a large additional exothermic heat effect was also found in the case of $\mathrm{Cu}$-nano-particles, due to the exchange chemical reaction between the $\mathrm{Cu}_{2} \mathrm{O}$ shell of the nano-particles and liquid $\mathrm{Sn}$; this is caused by the fact that the Cu-nano-particles are core-shell particles with an inner metallic $\mathrm{Cu}$ core and an outer $\mathrm{Cu}_{2} \mathrm{O}$ shell. This effect is less significant for Ni nano-particles which have a thinner oxide shell.

Received 25th December 2017 Accepted 20th February 2018

DOI: 10.1039/c7ra13643a

rsc.li/rsc-advances same time, there are only few studies dealing with changes in various other properties of NPs caused by their shape or internal structure. For instance, there is a number of papers dealing with the investigation of optical properties of metallic ${ }^{4,5}$ and bimetallic NPs. ${ }^{6-8}$ The extinction spectra of metal nanoparticles, such as $\mathrm{Ag}$ nanodisks and triangular prisms, Au multirods, as well as Au shell NPs with a pinhole (several $\mathrm{nm}$ ) structure were investigated in ref. 9. A bond-energy model for the calculation of the cohesive energy was developed in order to predict the size and shape dependency of various physical properties of metallic and bimetallic NPs with core/shell structure. ${ }^{10}$

The explosive growth in the number of studies of some classes of materials is mostly related to their prospective application. For instance, in order to promote new enhanced and customer-friendly lead-free solders, nanocomposite Snbased alloys with minor additions of metal nanoparticles have been under intensive scientific examination. ${ }^{11-13}$ Unfortunately, most of these studies refer to mechanical properties ${ }^{\mathbf{1 4}-\mathbf{1 8}}$ while information related to thermophysical and thermodynamic properties as well as structural features, especially in the liquid state, is scarce. ${ }^{19-21}$ However, a possible industrial use requires comprehensive data on new nanosized materials with precisely controlled properties. In particular, one needs reliable information on the thermodynamic stability of the employed metal nanoparticles in the bulk solder with respect to their possible dissolution during long time use. Therefore, new studies dealing with chemical and physical properties of metal NPs in a bulk metal matrix, depending on size, shape, composition, and structure of these NPs, are demanded.
${ }^{e}$ Bay Zoltan Ltd on Applied Research, BAY-ENG, 2 Igloi, Miskolc, Hungary-3519

${ }^{f}$ University Service Center for Transmission Electron Microscopy, Vienna University of Technology, Wiedner Hauptstrasse 8-10, A-1040 Vienna, Austria
${ }^{a}$ Department of Inorganic Chemistry - Functional Materials, Faculty of Chemistry, yakymovych@univie.ac.at

${ }^{b}$ Department of Metal Physics, Ivan Franko National University, Kyrylo and Mephodiy str. 8, 79005 Lviv, Ukraine

${ }^{c}$ Department of Nanotechnology, University of Miskolc, Miskolc-Egyetemváros,

Hungary-3515 
Table 1 Enthalpies of mixing data for the addition of bulk Cu into the liquid Sn-4.2Ag alloy; standard states: pure liquid metals

\begin{tabular}{|c|c|c|c|c|c|}
\hline Mol. Cu dropped & Measured enthalpy & \multicolumn{2}{|c|}{ Partial molar enthalpy } & \multicolumn{2}{|c|}{ Integral molar enthalpy } \\
\hline$n_{\mathrm{Cu}}\left(10^{-3}\right) \mathrm{mol}$ & $\Delta H_{\text {Signal }}^{*}\left(\mathrm{~J} \mathrm{~mol}^{-1}\right)$ & $x_{\mathrm{Cu}}{ }^{a}$ & $\Delta_{\mathrm{Mix}} \bar{H}_{\mathrm{Cu}}\left(\mathrm{J} \mathrm{mol}^{-1}\right)$ & $x_{\mathrm{Cu}}{ }^{b}$ & $\Delta_{\text {Mix }} H\left(\mathrm{~J} \mathrm{~mol}^{-1}\right)$ \\
\hline
\end{tabular}

$T=1073 \mathrm{~K}$; starting amount: $n_{\mathrm{Ag}}=1.8224 \times 10^{-3} \mathrm{~mol} ; n_{\mathrm{Sn}}=41.8071 \times 10^{-3} \mathrm{~mol}$

$\begin{array}{llll}0.5684 & 33518 \pm 604 & 0.0064 & -506 \pm 958 \\ 0.4250 & 33165 \pm 513 & 0.0176 & -858 \pm 1049 \\ 0.4547 & 33350 \pm 552 & 0.0272 & -673 \pm 1054 \\ 0.5055 & 33081 \pm 609 & 0.0375 & -942 \pm 1046 \\ 0.5484 & 33167 \pm 622 & 0.0485 & -856 \pm 1049 \\ 0.5490 & 32832 \pm 656 & 0.0598 & -1191 \pm 1038 \\ 0.5543 & 32678 \pm 659 & 0.0708 & -1345 \pm 1033 \\ 0.5728 & 32278 \pm 673 & 0.0818 & -1737 \pm 1021 \\ 0.5735 & 32305 \pm 674 & 0.0928 & -1718 \pm 1021 \\ 0.5861 & 32147 \pm 686 & 0.1036 & -1876 \pm 1016 \\ 0.6221 & 31584 \pm 715 & 0.1146 & -2439 \pm 999 \\ 0.6412 & 31509 \pm 735 & 0.1258 & -2514 \pm 996 \\ 0.6621 & 31693 \pm 764 & 0.1370 & -2330 \pm 1002 \\ 0.6729 & 31618 \pm 774 & 0.1483 & -2405 \pm 1000 \\ 0.6982 & 31383 \pm 797 & 0.1595 & -2640 \pm 992 \\ 0.6986 & 30800 \pm 783 & 0.1707 & -3223 \pm 974 \\ 0.7058 & 30738 \pm 790 & 0.1816 & -3285 \pm 972 \\ 0.8912 & 30456 \pm 988 & 0.1936 & -3567 \pm 963 \\ 0.9026 & 30035 \pm 987 & 0.2068 & -3989 \pm 950\end{array}$

$\begin{array}{ll} & 93 \\ 0.0129 & 91 \pm 7 \\ 0.0223 & 82 \pm 11 \\ 0.0321 & 73 \pm 24 \\ 0.0428 & 62 \pm 37 \\ 0.0542 & 51 \pm 50 \\ 0.0653 & 36 \pm 64 \\ 0.0763 & 20 \pm 77 \\ 0.0874 & -1 \pm 90 \\ 0.0982 & -21 \pm 103 \\ 0.1090 & -43 \pm 115 \\ 0.1201 & -73 \pm 128 \\ 0.1314 & -104 \pm 141 \\ 0.1427 & -133 \pm 154 \\ 0.1538 & -163 \pm 167 \\ 0.1651 & -196 \pm 180 \\ 0.1762 & -236 \pm 192 \\ 0.1870 & -276 \pm 204 \\ 0.2003 & -330 \pm 218 \\ 0.2133 & -389 \pm 232\end{array}$

$T=873 \mathrm{~K}$; first measurement; starting amount: $n_{\mathrm{Ag}}=1.7980 \times 10^{-3} \mathrm{~mol} ; n_{\mathrm{Sn}}=41.2485 \times 10^{-3} \mathrm{~mol}$

$\begin{array}{ll}0.2275 & 26836 \pm 367 \\ 0.2985 & 26834 \pm 481 \\ 0.3254 & 26633 \pm 521 \\ 0.3738 & 26326 \pm 591 \\ 0.3762 & 26383 \pm 596 \\ 0.4031 & 25741 \pm 623 \\ 0.4038 & 25659 \pm 623 \\ 0.4617 & 25844 \pm 717 \\ 0.4643 & 25883 \pm 722 \\ 0.4787 & 25618 \pm 737 \\ 0.5448 & 25135 \pm 823 \\ 0.5582 & 25443 \pm 853 \\ 0.5697 & 24608 \pm 842 \\ 0.6367 & 24833 \pm 950 \\ 0.8346 & 24284 \pm 1218\end{array}$

$\begin{array}{ll}0.0026 & -1445 \pm 1077 \\ 0.0087 & -1448 \pm 1077 \\ 0.0157 & -1648 \pm 1069 \\ 0.0235 & -1955 \pm 1056 \\ 0.0318 & -1898 \pm 1059 \\ 0.0402 & -2541 \pm 1033 \\ 0.0487 & -2622 \pm 1030 \\ 0.0577 & -2437 \pm 1037 \\ 0.0672 & -2398 \pm 1039 \\ 0.0766 & -2663 \pm 1028 \\ 0.0866 & -3147 \pm 1009 \\ 0.0972 & -2838 \pm 1021 \\ 0.1078 & -3674 \pm 987 \\ 0.1188 & -3448 \pm 996 \\ 0.1318 & -3997 \pm 974\end{array}$

0.0053

0.0121

0.0194

0.0277

0.0359

0.0445

0.0530

0.0625

0.0719

0.0814

0.0919

0.1025

0.1130

0.1245

0.1391

168

$157 \pm 8$

$146 \pm 19$

$133 \pm 31$

$116 \pm 44$

$99 \pm 57$

$76 \pm 71$

$52 \pm 84$

$27 \pm 98$

$3 \pm 113$

$-25 \pm 128$

$-61 \pm 143$

$-93 \pm 160$

$-135 \pm 175$

$-178 \pm 192$

$-242 \pm 213$

$T=873 \mathrm{~K}$; second measurement; starting amount: $n_{\mathrm{Ag}}=1.7652 \times 10^{-3} \mathrm{~mol} ; n_{\mathrm{Sn}}=40.4961 \times 10^{-3} \mathrm{~mol}$

\begin{tabular}{|c|c|c|c|c|c|}
\hline & & & & & 168 \\
\hline 0.5287 & $27335 \pm 736$ & 0.0062 & $-1056 \pm 994$ & 0.0124 & $150 \pm 17$ \\
\hline 0.5341 & $26341 \pm 717$ & 0.0184 & $-2049 \pm 958$ & 0.0245 & $123 \pm 33$ \\
\hline 0.5679 & $26795 \pm 775$ & 0.0308 & $-1595 \pm 974$ & 0.0371 & $100 \pm 50$ \\
\hline 0.5970 & $26517 \pm 807$ & 0.0436 & $-1873 \pm 964$ & 0.0501 & $74 \pm 67$ \\
\hline 0.6165 & $26133 \pm 821$ & 0.0693 & $-2257 \pm 950$ & 0.0757 & $9 \pm 101$ \\
\hline 0.6252 & $25237 \pm 804$ & 0.0819 & $-3153 \pm 918$ & 0.0881 & $-34 \pm 117$ \\
\hline 0.6330 & $25837 \pm 833$ & 0.0943 & $-2553 \pm 939$ & 0.1004 & $-67 \pm 132$ \\
\hline 0.6838 & $24527 \pm 855$ & 0.1306 & $-3863 \pm 892$ & 0.1367 & $-204 \pm 178$ \\
\hline 0.7186 & $24314 \pm 890$ & 0.1429 & $-4076 \pm 884$ & 0.1492 & $-260 \pm 193$ \\
\hline 0.7401 & $24488 \pm 924$ & 0.1554 & $-3902 \pm 890$ & 0.1617 & $-313 \pm 208$ \\
\hline 0.7588 & $23746 \pm 918$ & 0.1679 & $-4644 \pm 863$ & 0.1741 & $-377 \pm 222$ \\
\hline 0.7771 & $23671 \pm 937$ & 0.1803 & $-4719 \pm 861$ & 0.1865 & $-442 \pm 237$ \\
\hline
\end{tabular}

${ }^{a}$ Average of $x_{\mathrm{Cu}}$ before and after drop. ${ }^{b}$ Per mole of the mixture. 
In the present study, a drop calorimetric method is used to investigate the "thermodynamic nanoeffects". A Sn-3.8Ag-0.7Cu alloy (SAC387; in wt\%) was employed in the performed study as the main component since SAC387 is a commercially available solder. Many papers are dealing with nanocomposite $\mathrm{Sn}-\mathrm{Ag}-\mathrm{Cu}$ (SAC) solders, attempting to improve their properties by minor additions of metal NPs such as $\mathrm{Co}, \mathrm{Cu}, \mathrm{Fe}, \mathrm{Ni}$, etc. ${ }^{17,22}$ The nanocomposite SAC solder is reflowed during the soldering process, and reactive metal NPs are dissolved in the liquid Snbased matrix. Therefore, the present research provides essential data to simulate the soldering process using nanocomposite solders with nano-sized metal additions in a proper way. The heat effects caused by the dissolution of $\mathrm{Cu}$ and $\mathrm{Ni}$ in bulk as well as in nanosized form were determined and the excess surface enthalpies of the employed NPs were derived. The experimental results are theoretically described taking into account not only the size but also the internal structure of the nanoparticles, i.e. their apparent core-shell (metal core/oxide shell) structure.

\section{Results and discussion}

Calorimetric measurements. The present study was started with calorimetric measurements, adding pieces of bulk $\mathrm{Cu}$ into a liquid Sn-4.2Ag alloy (in at\%) (Table 1), where the molar enthalpy of mixing for the liquid Sn-4.2Ag alloy was taken from Flandorfer et al. ${ }^{23}$ Since the concentration values in figures and tables are given in at\%, the composition of the SAC387 master alloy is also converted to at\%, resulting in a composition Sn4.1Ag-1.3Cu. The measurements were performed at $1073 \mathrm{~K}$ and $873 \mathrm{~K}$; they were compared with data calculated by a Redlich-Kister-Muggianu polynomial based on literature data by Luef et al. ${ }^{24}$

Fig. 1 shows very good agreement between experimental values and calculated curves, taking into account that the experimental data of ref. 24 were obtained at temperatures different from the present ones, namely $773 \mathrm{~K}, 973 \mathrm{~K}$ and $1173 \mathrm{~K}$. The corresponding values of the integral enthalpy of mixing for the liquid $\mathrm{Sn}-4.1 \mathrm{Ag}-1.3 \mathrm{Cu}$ alloy were then used as the starting values required for the evaluation of $\Delta_{\text {Mix }} H$ of quaternary liquid $\mathrm{Ag}-\mathrm{Cu}-\mathrm{Ni}-\mathrm{Sn}$ alloys. As evident from Fig. 1, the deviation

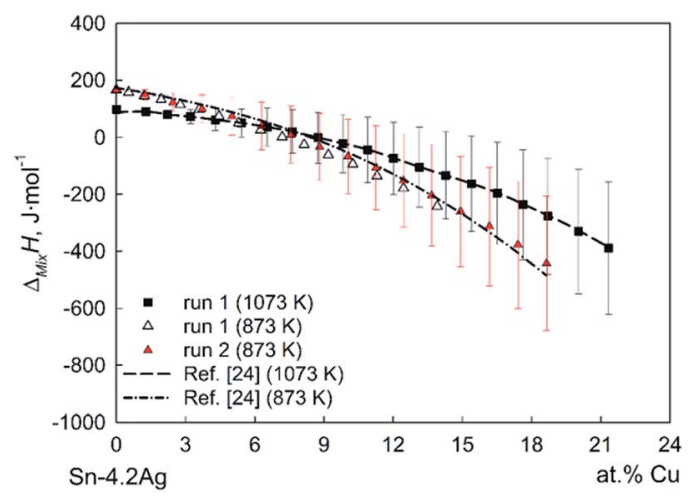

Fig. 1 Integral enthalpy of mixing of liquid $(\mathrm{Sn}-4.2 \mathrm{Ag})_{100-x} \mathrm{Cu}_{x}$ alloys. from ideal behavior (enthalpy of mixing is equal to zero) is more significant at the lower temperature, in full accord with the general expectation for systems with chemical compounds. ${ }^{25}$

The experimental values for the $\mathrm{Ag}-\mathrm{Cu}-\mathrm{Ni}-\mathrm{Sn}$ system are presented in Table 2, and they are compared with literature data by Saeed et al., ${ }^{26}$ obtained at $1273 \mathrm{~K}$, in Fig. 2. In order to describe the molar enthalpy of mixing for liquid quaternary alloys, it was suggested to modify the Redlich-Kister-Muggianu polynomial by adding an additional term corresponding to symmetric quaternary interactions. ${ }^{26}$ As seen from Fig. 2, there is a reasonably good agreement between experimental and calculated data with a maximum difference of less than $1 \mathrm{~kJ} \mathrm{~mol}^{-1}$.

The results in Table 3 differ from those in Tables 1 and 2 by the experimental procedure: they were obtained by dropping pieces of $\mathrm{Cu}$ or $\mathrm{Ni}$ wrapped in a $\mathrm{Sn}-4.1 \mathrm{Ag}-1.3 \mathrm{Cu}$ foil into the liquid alloy in the calorimeter at $1073 \mathrm{~K}$ and $873 \mathrm{~K}$. These measurements were performed to ensure that no significant side effects would be observed when dropping NPs wrapped into such a foil into the calorimeter. As seen from Fig. 3a and b, very good agreement was obtained between experimental results with and without employing the $\mathrm{Sn}-4.1 \mathrm{Ag}-1.3 \mathrm{Cu}$ foil. It should also be noted that, in contrast to the ternary $\mathrm{Ag}-\mathrm{Cu}-\mathrm{Sn}$ alloys (Fig. 1), the quaternary $\mathrm{Ag}-\mathrm{Cu}-\mathrm{Ni}-\mathrm{Sn}$ alloys did not show any significant temperature dependence of the molar mixing enthalpies (Fig. 2 and $3 \mathrm{~b}$ ). The present results of the partial enthalpy of mixing for ternary and quaternary alloys were exothermic in the investigated concentration range at both temperatures while the integral enthalpy of mixing for the ternary (Sn-4.1Ag-1.3Cu)-Cu alloys changes from positive to negative values with increasing $\mathrm{Cu}$ content. Furthermore, the experimental data for the ternary $(\mathrm{Sn}-4.1 \mathrm{Ag}-1.3 \mathrm{Cu})-\mathrm{Cu}$ alloys indicated a clear temperature and concentration dependence of the integral enthalpy of mixing, with a tendency to more exothermic values at lower temperatures and higher $\mathrm{Cu}$ contents.

The microstructure analysis of the samples after calorimetric measurements showed that the intermetallic compounds (IMCs) $\mathrm{Ag}_{3} \mathrm{Sn}, \mathrm{Cu}_{6} \mathrm{Sn}_{5}$ and $\mathrm{Ni}_{3} \mathrm{Sn}_{4}$ had been formed during the solidification of the investigated $\mathrm{Ag}-\mathrm{Cu}-\mathrm{Ni}-\mathrm{Sn}$ samples (Fig. 4a$\mathrm{d}$, Table 4). These results are in very good agreement with the quaternary $\mathrm{Ag}-\mathrm{Cu}-\mathrm{Ni}-\mathrm{Sn}$ phase diagram. ${ }^{27}$ According to SEM analyses of the investigated samples, a substitution of $\mathrm{Ni}$ and $\mathrm{Cu}$ atoms, respectively, was observed in the IMCs $\mathrm{Cu}_{6} \mathrm{Sn}_{5}$ and $\mathrm{Ni}_{3} \mathrm{Sn}_{4}$. This effect is more pronounced for $(\mathrm{Cu}, \mathrm{Ni})_{6} \mathrm{Sn}_{5}$ due to a significantly increasing exothermic enthalpy of formation of this compound on admixture of $\mathrm{Ni}^{28}$ In the $\mathrm{Sn}_{76} \mathrm{Ag}_{3} \mathrm{Cu}_{21}$ alloy, two $\mathrm{Cu}-\mathrm{Sn}$ IMCs were found, namely $\mathrm{Cu}_{3} \mathrm{Sn}$ and $\mathrm{Cu}_{6} \mathrm{Sn}_{5}$. According to the $\mathrm{Cu}-\mathrm{Sn}$ phase diagram, $\mathrm{Cu}_{3} \mathrm{Sn}$ should be formed in the investigated alloy during cooling and should decompose under equilibrium conditions into pure $\mathrm{Sn}$ and $\mathrm{Cu}_{6} \mathrm{Sn}_{5}$ at $681 \mathrm{~K} .^{29}$ However, the cooling of the sample after the calorimetric measurement was certainly not slow enough to reach an equilibrium state, thus $\mathrm{Cu}_{3} \mathrm{Sn}$ grains are left as can be seen in the microstructure.

After the experiments with bulk $\mathrm{Cu}$ and $\mathrm{Ni}$, the corresponding experiments with nano-particles were performed (Tables 5 and 6). The excess enthalpies due to the nano-effect were 
Table 2 Enthalpies of mixing data for the addition of bulk Ni into the liquid Sn-4.1Ag-1.3Cu alloy; standard states: pure liquid metals

\begin{tabular}{|c|c|c|c|c|c|}
\hline \multirow{2}{*}{$\frac{\text { Mol. Ni dropped }}{n_{\mathrm{Ni}}\left(10^{-3} \mathrm{~mol}\right)}$} & \multirow{2}{*}{$\begin{array}{l}\text { Measured enthalpy } \\
\Delta H_{\text {Signal }}^{*}\left(\mathrm{~J} \mathrm{~mol}^{-1}\right) \\
\end{array}$} & \multicolumn{2}{|c|}{ Partial molar enthalpy } & \multicolumn{2}{|c|}{ Integral molar enthalpy } \\
\hline & & $x_{\mathrm{Ni}}^{a}$ & $\Delta_{\mathrm{Mix}} \bar{H}_{\mathrm{Ni}}\left(\mathrm{J} \mathrm{mol}^{-1}\right)$ & $x_{\mathrm{Ni}}^{b}$ & $\Delta_{\mathrm{Mix}} H\left(\mathrm{~J} \mathrm{~mol}^{-1}\right.$ \\
\hline 1.1040 & $-9226 \pm 667$ & 0.0132 & $-49894 \pm 650$ & 0.0263 & $-1225 \pm 16$ \\
\hline 1.1889 & $-9214 \pm 718$ & 0.0398 & $-49882 \pm 649$ & 0.0532 & $-2567 \pm 32$ \\
\hline 1.6360 & $-11267 \pm 1208$ & 0.1224 & $-51935 \pm 794$ & 0.1378 & $-6919 \pm 91$ \\
\hline \multicolumn{6}{|c|}{$T=1073 \mathrm{~K}$; second measurement; starting amount: $n_{\mathrm{Ag}}=1.7825 \times 10^{-3} \mathrm{~mol} ; n_{\mathrm{Cu}}=0.5574 \times 10^{-3} \mathrm{~mol} ; n_{\mathrm{Sn}}=40.7056 \times 10^{-3} \mathrm{~mol}$} \\
\hline & & & & & 93 \\
\hline 0.2259 & $-9155 \pm 135$ & 0.0026 & $-49719 \pm 643$ & 0.0052 & $-169 \pm 15$ \\
\hline 0.2769 & $-9283 \pm 168$ & 0.0084 & $-49848 \pm 652$ & 0.0115 & $-485 \pm 30$ \\
\hline 0.4248 & $-10111 \pm 280$ & 0.0471 & $-50676 \pm 711$ & 0.0515 & $-2505 \pm 105$ \\
\hline 0.4646 & $-10129 \pm 307$ & 0.0564 & $-50693 \pm 712$ & 0.0612 & $-2993 \pm 119$ \\
\hline 0.5238 & $-9884 \pm 338$ & 0.0665 & $-50449 \pm 695$ & 0.0718 & $-3529 \pm 133$ \\
\hline 0.5556 & $-10511 \pm 381$ & 0.0773 & $-51076 \pm 739$ & 0.0828 & $-4092 \pm 147$ \\
\hline 0.5738 & $-11319 \pm 424$ & 0.0883 & $-51884 \pm 796$ & 0.0938 & $-4669 \pm 162$ \\
\hline 0.5936 & $-11034 \pm 428$ & 0.0994 & $-51599 \pm 775$ & 0.1050 & $-5249 \pm 176$ \\
\hline 0.6200 & $-11567 \pm 468$ & 0.1107 & $-52132 \pm 813$ & 0.1164 & $-5845 \pm 190$ \\
\hline 0.6274 & $-11251 \pm 461$ & 0.1220 & $-51816 \pm 791$ & 0.1276 & $-6430 \pm 204$ \\
\hline 0.6874 & $-12276 \pm 551$ & 0.1336 & $-52841 \pm 863$ & 0.1396 & $-7067 \pm 218$ \\
\hline
\end{tabular}

$T=873 \mathrm{~K}$; first measurement; starting amount: $n_{\mathrm{Ag}}=1.7086 \times 10^{-3} \mathrm{~mol} ; n_{\mathrm{Cu}}=0.5343 \times 10^{-3} \mathrm{~mol} ; n_{\mathrm{Sn}}=39.0184 \times 10^{-3} \mathrm{~mol}$

\begin{tabular}{|c|c|c|c|c|c|}
\hline & & & & & 152 \\
\hline 0.3278 & $-18316 \pm 423$ & 0.0113 & $-52658 \pm 1108$ & 0.0152 & $-652 \pm 20$ \\
\hline 0.5430 & $-17950 \pm 686$ & 0.0215 & $-52292 \pm 1086$ & 0.0278 & $-1312 \pm 35$ \\
\hline 0.5684 & $-18800 \pm 752$ & 0.0342 & $-53142 \pm 1137$ & 0.0406 & $-1997 \pm 53$ \\
\hline
\end{tabular}

$T=873 \mathrm{~K}$; second measurement; starting amount: $n_{\mathrm{Ag}}=3.5225 \times 10^{-3} \mathrm{~mol} ; n_{\mathrm{Cu}}=1.1015 \times 10^{-3} \mathrm{~mol} ; n_{\mathrm{Sn}}=80.4407 \times 10^{-3} \mathrm{~mol}$

$\begin{array}{llllrl}1.2447 & -18830 \pm 1419 & 0.0072 & -53125 \pm 1140 & 0.0144 & -619 \pm 16 \\ 1.2190 & -18733 \pm 1383 & 0.0213 & -53029 \pm 1135 & 0.0281 & -1349 \pm 32 \\ 0.4438 & -18926 \pm 509 & 0.0306 & -53221 \pm 1146 & -1610 \pm 38 \\ 0.4800 & -18996 \pm 552 & 0.0357 & -53291 \pm 1150 & 0.0383 \\ 0.4846 & -18669 \pm 548 & 0.0409 & -52965 \pm 1131 & 0.0435 & -1891 \pm 44 \\ 0.5128 & -18822 \pm 585 & 0.0463 & -53117 \pm 1140 & 0.0490 & -2169 \pm 50 \\ 0.5463 & -19068 \pm 631 & 0.0519 & -53364 \pm 1155 & 0.0548 & -2461 \pm 56\end{array}$

${ }^{a}$ Average of $x_{\mathrm{Ni}}$ before and after drop. ${ }^{b}$ Per mole of the mixture.

estimated, similarly as in ref. 19, by comparing the measured enthalpy values obtained with bulk and nanosized particles (Fig. 5 and 6).

In order to estimate values of the excess enthalpy, the concentration dependencies of the measured enthalpy for additions of $\mathrm{Cu}$ and $\mathrm{Ni}$ in bulk and nanosized form were plotted as a function of the content of the added element and extrapolated to zero. The estimated value of $\Delta H_{\mathrm{i} \text {,nano }}^{\mathrm{ex}}$ for $\mathrm{Cu}$ additions was found to be about $-17.0 \pm 1.2 \mathrm{~kJ} \mathrm{~mol}^{-1}$ at $1073 \mathrm{~K}$ and -18.5 $\pm 1.3 \mathrm{~kJ} \mathrm{~mol}^{-1}$ at $873 \mathrm{~K}$ (Fig. 5). The corresponding value of $\Delta H_{\mathrm{i}, \text { nano }}^{\mathrm{ex}}$ for Ni was found as about $-3.8 \pm 1.6 \mathrm{~kJ} \mathrm{~mol}^{-1}$ at $1073 \mathrm{~K}$ and $-3.3 \pm 1.5 \mathrm{~kJ} \mathrm{~mol}^{-1}$ at $873 \mathrm{~K}$ (Fig. 6).

The TEM analysis together with HAADF STEM (high angle annular dark field - scanning transmission electron

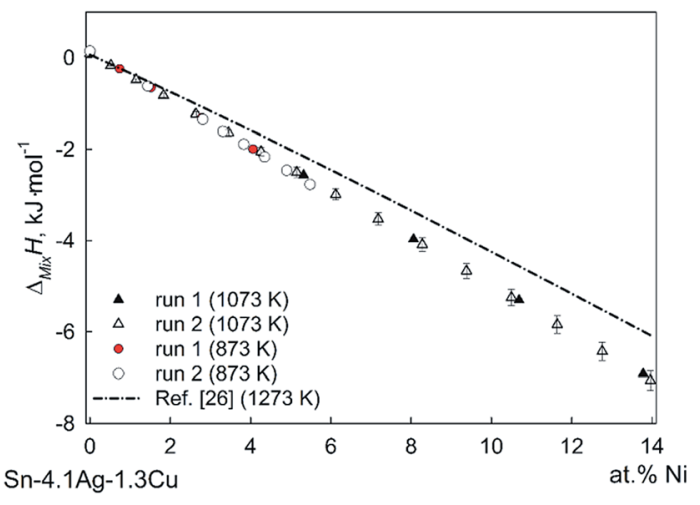

Fig. 2 Integral enthalpy of mixing of liquid $(\mathrm{Sn}-4.1 \mathrm{Ag}-1.3 \mathrm{Cu})_{100-{ }_{-} \mathrm{Ni}}$ alloys. 
Table 3 Enthalpies of mixing data for the addition of both packed bulk Cu and Ni into the liquid Sn-4.1Ag-1.3Cu alloy; standard states: pure liquid metals

Mol. packed

dropped metal
Measured enthalpy Partial molar enthalpy

$\Delta H_{\text {Signal }}^{*}\left(\mathrm{~J} \mathrm{~mol}^{-1}\right) \quad x_{\mathrm{Cu}}{ }^{a} \quad \Delta_{\mathrm{Mix}} \bar{H}_{\mathrm{Cu}}\left(\mathrm{J} \mathrm{mol}^{-1}\right)$

$x_{\mathrm{Cu}}{ }^{a} \quad \Delta_{\mathrm{Mix}} \bar{H}_{\mathrm{Cu}}\left(\mathrm{J} \mathrm{mol}^{-1}\right)$

Integral molar enthalpy

$\Delta_{\mathrm{Cu}}{ }^{b} \quad \Delta_{\mathrm{Mix}} H\left(\mathrm{~J} \mathrm{~mol}^{-1}\right)$

$T=1073 \mathrm{~K}$; starting amount: $n_{\mathrm{Ag}}=2.0639 \times 10^{-3} \mathrm{~mol} ; n_{\mathrm{Cu}}=0.6454 \times 10^{-3} \mathrm{~mol} ; n_{\mathrm{Sn}}=47.1327 \times 10^{-3} \mathrm{~mol}$

$\begin{array}{lll}0.6101 & 33431 \pm 654 & 0.0060 \\ 0.6273 & 33021 \pm 692 & 0.0181 \\ 0.6580 & 32527 \pm 722 & 0.0302 \\ 0.6816 & 32532 \pm 761 & 0.0425 \\ 0.7116 & 32707 \pm 790 & 0.0548 \\ 0.7181 & 32267 \pm 821 & 0.0670 \\ 0.7284 & 32090 \pm 789 & 0.0790 \\ 0.7326 & 32363 \pm 787 & 0.0907 \\ 0.7487 & 31614 \pm 862 & 0.1022 \\ 0.7657 & 31775 \pm 857 & 0.1135 \\ 0.7762 & 31465 \pm 813 & 0.1247 \\ 0.7933 & 31575 \pm 877 & 0.1357 \\ 0.8448 & 31104 \pm 859 & 0.1468 \\ 0.8656 & 31181 \pm 893 & 0.1582 \\ 0.8783 & 30703 \pm 853 & 0.1694 \\ 0.9206 & 30828 \pm 906 & 0.1807 \\ 0.9556 & 30679 \pm 965 & 0.1920 \\ 0.9794 & 30405 \pm 1046 & 0.2031 \\ 1.1165 & 29964 \pm 972 & 0.2149 \\ 1.1578 & 29959 \pm 960 & 0.2278\end{array}$

93

$85 \pm 13$

$73 \pm 26$

$56 \pm 40$

$38 \pm 53$

$22 \pm 67$

$1 \pm 81$

$-22 \pm 94$

$-42 \pm 106$

$-69 \pm 119$

$-96 \pm 132$

$-125 \pm 144$

$-153 \pm 156$

$-188 \pm 167$

$-222 \pm 178$

$-262 \pm 189$

$-301 \pm 200$

$-342 \pm 211$

$-385 \pm 223$

$-443 \pm 233$

$-501 \pm 243$

${ }^{a}$ Average of $x_{\mathrm{Cu}} / x_{\mathrm{Ni}}$ before and after drop. ${ }^{b}$ Per mole of the mixture.

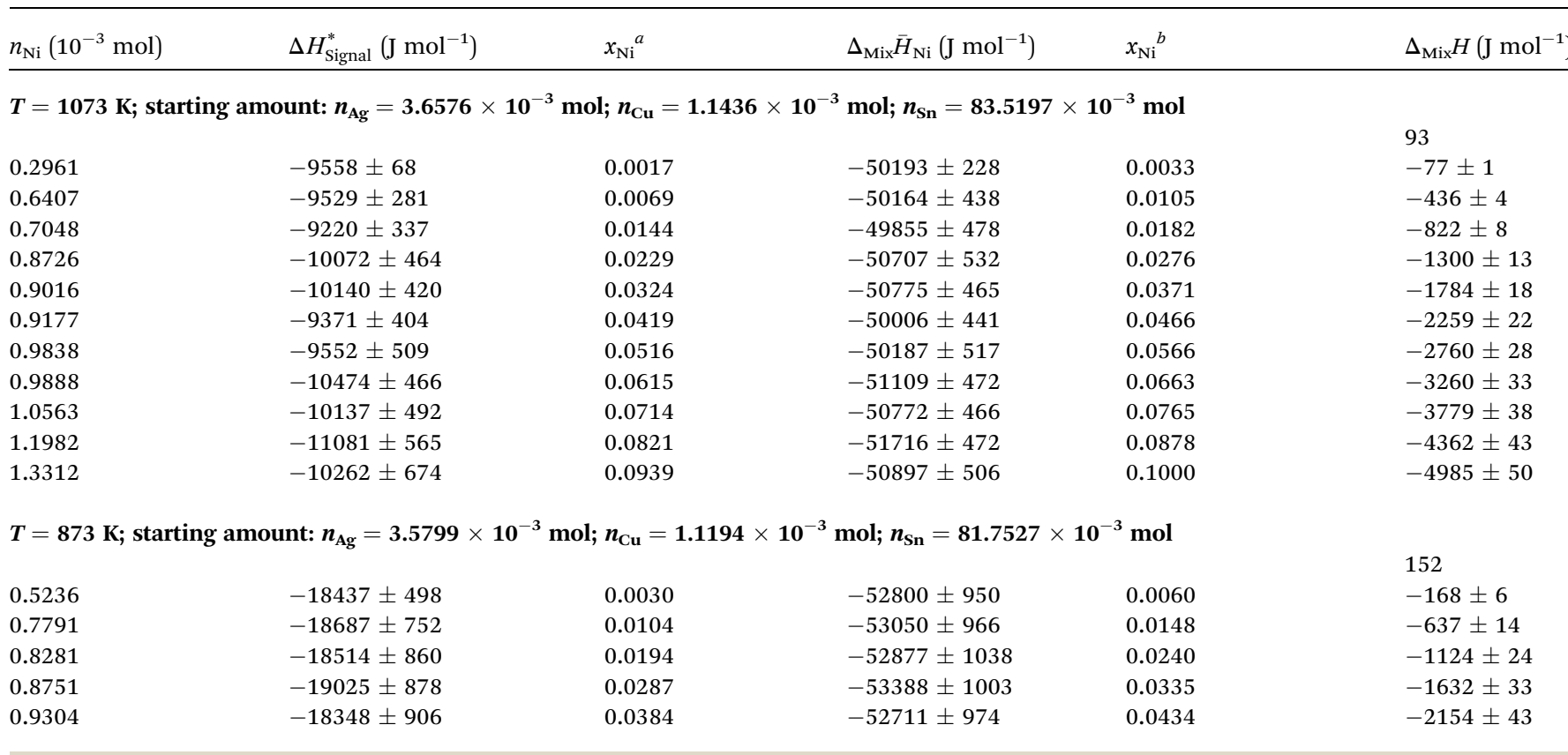

microscopy) imaging should bring essential information about the characteristics of the employed $\mathrm{Cu}$ and Ni NPs in order to explain the significant difference in the values of the excess surface enthalpy. Fig. 7 and 8 show examples of the TEM micrographs of $\mathrm{Cu}$ and Ni NPs which show that the NPs (including oxide shell) are of similar size, considering the original size distribution.
Furthermore, EDX elemental mapping of Cu NPs showed an oxide shell $\left(\mathrm{Cu}_{2} \mathrm{O}\right)$ covering a metal core (Fig. $\left.7(\mathrm{a}-\mathrm{c})\right)$. These data are in a good agreement with XRD analysis indicating the presence of both $\mathrm{Cu}$ and $\mathrm{Cu}_{2} \mathrm{O}$ (cubic, see ref. 30) in the investigated $\mathrm{Cu}$ nanopowder (Fig. 9a). In the case of Ni NPs, only traces of $\mathrm{NiO}$ (trigonal/rhombohedral, see ref. 31) with very low intensity were found in the XRD pattern (Fig. 9b); only minor 

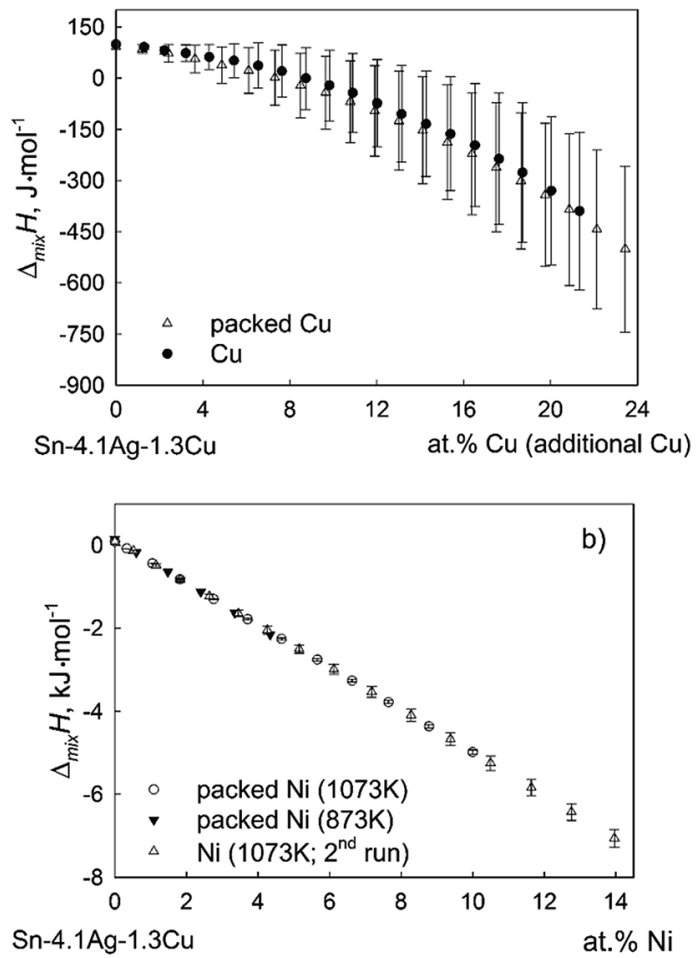

Fig. 3 Integral enthalpy of mixing of liquid $(\mathrm{Sn}-4.1 \mathrm{Ag}-1.3 \mathrm{Cu})_{100-x} \mathrm{Cu}_{x}$ alloys at $1073 \mathrm{~K}(\mathrm{a})$ and $(\mathrm{Sn}-4.1 \mathrm{Ag}-1.3 \mathrm{Cu})_{100-} \mathrm{Ni}_{x}$ alloys at $1073 \mathrm{~K}$ and $873 \mathrm{~K}(\mathrm{~b})$.
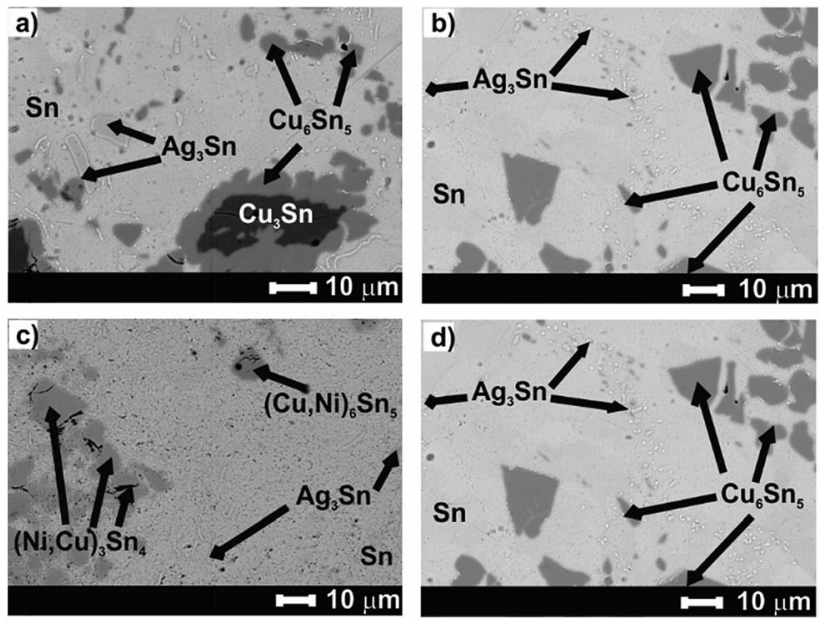

Fig. 4 BSE micrographs of $(\mathrm{Sn}-4.1 \mathrm{Ag}-1.3 \mathrm{Cu})_{100-x} \mathrm{Cu}_{x}(\mathrm{a})-\mathrm{Sn}_{76} \mathrm{Ag}_{3^{-}}$ $\mathrm{Cu}_{21} ;$ (b) $\left.-\mathrm{Sn}_{83} \mathrm{Ag}_{4} \mathrm{Cu}_{13}\right)$ and $(\mathrm{Sn}-4.1 \mathrm{Ag}-1.3 \mathrm{Cu})_{100-x} \mathrm{Ni}_{x}$ (c) $-\mathrm{Sn}_{81} \mathrm{Ag}_{4^{-}}$ $\mathrm{Cu}_{1} \mathrm{Ni}_{14} ;$ (d) $\left.-\mathrm{Sn}_{91} \mathrm{Ag}_{4} \mathrm{Cu}_{1} \mathrm{Ni}_{4}\right)$ samples after calorimetry.

amounts of oxygen were found on the surface of the Ni NPs (Fig. $8 \mathrm{~b}$ and c). The first broad peak in the X-ray patterns is caused by the specimen holder with the polycarbonate cap.

Pore size distributions of $\mathrm{Cu}$ and Ni NPs were measured by nitrogen sorption according to the theory of Barrett, Joyner and Halenda (BJH) (Fig. 10a and b). The determined BET surface area of the employed NPs is equal to $(10.6 \pm 0.4) 10^{3} \mathrm{~m}^{2} \mathrm{~kg}^{-1}$ for $\mathrm{Cu}$ NPs and $(10.2 \pm 0.4) 10^{3} \mathrm{~m}^{2} \mathrm{~kg}^{-1}$ for Ni NPs.

\section{Theoretical considerations}

The goal of this chapter is to model the observed

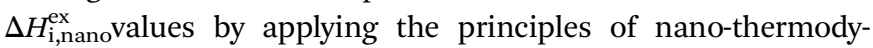
namics. ${ }^{32-34}$ In a previous paper ${ }^{19}$ the nano-effect was described as

$$
\Delta H_{\mathrm{i}, \text { nano }}^{\mathrm{ex}}=-A_{\mathrm{BET}} M \sigma_{\mathrm{sg}, \mathrm{H}, T_{\mathrm{D}}}
$$

where $A_{\mathrm{BET}}\left(\mathrm{m}^{2} \mathrm{~g}^{-1}\right)$ is the BET surface area of the nano-particles (which is assumed to be negligible for bulk material), $M$ ( $\mathrm{g}$ $\left.\mathrm{mol}^{-1}\right)$ is the molar mass of the nano-particles, $\sigma_{\mathrm{sg}, \mathrm{H}, T_{\mathrm{D}}}\left(\mathrm{J} \mathrm{m}^{-2}\right)$ is the enthalpy part of the surface energy of the solid nanoparticles at the drop temperature. (Note that in the present paper the sign of $\Delta H_{\mathrm{i}, \text { nano }}^{\mathrm{ex}}$ is kept positive contrary to the previous paper, ${ }^{19}$ thus a negative sign appears in eqn (1); this is done for two reasons: to avoid predicting anything before the experiments are run, and to make more obvious that the nanoeffect is exothermic). The physical meaning of eqn (1) is the loss (see the negative sign) of the enthalpy part of the surface energy of the nano-particles upon dissolution per mole of metal added. The calculated and experimental results for the systems studied in this paper are compared in Table 7.

As follows from Table 7, the experimental values in this case are considerably more negative than the calculated ones, and this difference is especially striking for $\mathrm{Cu}$ nanoparticles. This is most probably due to the fact that eqn (1) is strictly valid only for pure metallic nano-particles without any oxide shell. However, as observed by the TEM and XRD investigations of the nanoparticles (see Fig. 6-8), the Cu-nano-particles are severely contaminated by oxygen. Actually, instead of $\mathrm{Cu}$-nano-particles we have core/shell nano-particles with a $\mathrm{Cu}$ inner core $(\alpha)$ and a $\mathrm{Cu}_{2} \mathrm{O}$ shell $(\beta)$, which form together particle $\gamma$. A similar oxidation problem exists also for Ni nano-particles, however, to a much smaller extent. Therefore, the previous model in eqn (1) has to be modified to take into account the role of the oxide shells on the metallic nano-particles, too.

When the experiments were performed, it was assumed that $n_{\text {Me }}^{0}$ (mole) of pure metal was added into the calorimeter. Instead, the molar part $y$ of these nano-particles was actually oxidized so that in fact the following amounts of matter were added:

$$
\begin{gathered}
n_{\alpha}=(1-y) n_{\mathrm{Me}}^{0}, \\
n_{\beta}=y n_{\mathrm{Me}}^{0},
\end{gathered}
$$

where $\alpha$ denotes the added metal, and $\beta$ denotes its oxide shell $\mathrm{MeO}_{x}$ (where the stoichiometry is always written such that the oxide molecule contains one metallic atom, i.e., $x$ can be any positive number). Thus, in addition to eqn (1), there are two additional terms for the enthalpy nano-effect: one is responsible for different heat capacities of $\alpha$ (metal) and $\beta$ (oxide), while the other one is responsible for the chemical interaction between $\beta$ and metal atoms in the liquid alloy (in our case these are mostly atoms of $\mathrm{Sn}$ ), into which the nano-particles are added:

$$
\Delta H_{\alpha / \beta, \text { nano }}^{\mathrm{ex}}=-A_{\mathrm{BET}} M_{\gamma} \sigma_{\gamma, \mathrm{H}, T_{\mathrm{D}}}+y\left(\Delta H_{\mathrm{C}_{\mathrm{p}}}+\Delta_{\mathrm{r}} \mathrm{H}^{0}\right),
$$


Table 4 SEM-EDX results of $(\mathrm{Sn}-4.1 \mathrm{Ag}-1.3 \mathrm{Cu})_{100-x} \mathrm{Cu}_{x}$ and $(\mathrm{Sn}-4.1 \mathrm{Ag}-1.3 \mathrm{Cu})_{100-x} \mathrm{Ni}_{x}$ samples after calorimetry

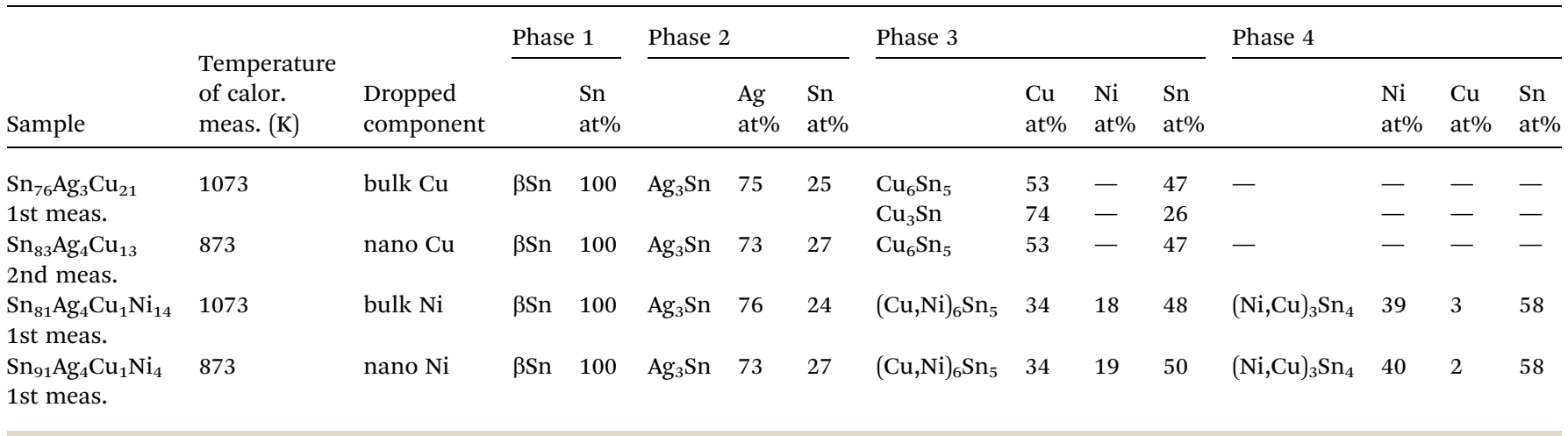

where $M_{\gamma}$ is the average molar mass of the partly oxidized particle as defined by eqn (5), $\sigma_{\gamma, \mathrm{H}, T_{\mathrm{D}}}$ is the effective enthalpy part of the surface energy of the partly oxidized particle as defined by eqn (6), and $\Delta H_{\mathrm{C}_{\mathrm{p}}}\left(\mathrm{J} \mathrm{mol}^{-1}\right)$ is the enthalpy difference due to the different heat capacities of the oxide and the metal as defined by eqn (7); $\Delta_{r} H^{0}\left(\mathrm{~J} \mathrm{~mol}^{-1}\right)$ is the standard molar enthalpy change of the chemical reaction: $\mathrm{MeO}_{x}+y \mathrm{Sn}=\mathrm{Sn}_{y} \mathrm{O}_{x}+$ Me (or, which is the same: $\beta+y \operatorname{Sn}=\operatorname{Sn}_{y} \mathrm{O}_{x}+\alpha$, where the stoichiometry is always written such that the oxide molecule contains one metallic atom, i.e., $x$ can be any positive number):

$$
\begin{gathered}
M_{\gamma}=(1-y) M_{\alpha}+y M_{\beta}, \\
\sigma_{\gamma, \mathrm{H}, T_{\mathrm{D}}} \cong \sigma_{\alpha / \beta, \mathrm{H}, T_{\mathrm{D}}}+\sigma_{\beta, \mathrm{H}, T_{\mathrm{D}}}+\left(\sigma_{\alpha, \mathrm{H}, T_{\mathrm{D}}}-\sigma_{\alpha / \beta, \mathrm{H}, T_{\mathrm{D}}}\right. \\
\left.-\sigma_{\beta, \mathrm{H}, T_{\mathrm{D}}}\right) \exp \left(-\frac{d}{\delta}\right) \\
\Delta H_{\mathrm{C}_{\mathrm{P}}}=\int_{T_{\mathrm{D}}}^{T_{\mathrm{M}}}\left(C_{\mathrm{P}, \beta}-C_{\mathrm{P}, \alpha}\right) \mathrm{d} T
\end{gathered}
$$

where $M_{\alpha}\left(\mathrm{g} \mathrm{mol}^{-1}\right)$ is the molar mass of the metal core, $M_{\beta}$ $\left(\mathrm{g} \mathrm{mol}^{-1}\right)$ is the molar mass of the oxide shell, $\sigma_{\alpha / \beta, \mathrm{H}, T_{\mathrm{D}}}\left(\mathrm{J} \mathrm{m}^{-2}\right)$ is the enthalpy part of the $\alpha / \beta$ interfacial energy, $\sigma_{\beta, \mathrm{H}, T_{\mathrm{D}}}\left(\mathrm{J} \mathrm{m}^{-2}\right)$ is the enthalpy part of the surface energy of the oxide shell, $\sigma_{\alpha, \mathrm{H}, T_{\mathrm{D}}}$ $\left(\mathrm{J} \mathrm{m}^{-2}\right)$ is the enthalpy part of the surface energy of the metallic core, $d(\mathrm{~nm})$ is the thickness of the oxide shell, $\delta \cong 1 \mathrm{~nm}$ is the coefficient in the separation dependence of interfacial energies, ${ }^{36}$ $C_{\mathrm{P}, \beta}\left(\mathrm{J}(\mathrm{mol} \mathrm{K})^{-1}\right)$ is the molar heat capacity of the oxide shell of the nano-particle, $C_{\mathrm{P}, \alpha}\left(\mathrm{J}(\mathrm{mol} \mathrm{K})^{-1}\right)$ is the molar heat capacity of the metallic inner core of the nano-particle. When the oxide shell is thin, it is modelled as a shell of constant thickness following the original shape of the nano-particle. If this thickness is much smaller than the radius of the nano-particle, the BET surfacse area of the outer oxide/gas surface and the BET interfacial area of the inner metal/oxide interface are considered equal.

In order to check whether the proposed reactions are exergonic and favorable or not, the free energy change for the reactions was estimated from the Gibbs energy of formation values of the oxides of copper $\left(\Delta_{\mathrm{f}} G_{\mathrm{Cu}_{2} \mathrm{O}}\right)$, nickel $\left(\Delta_{\mathrm{f}} G_{\mathrm{NiO}}\right)$ and tin $\left(\Delta_{\mathrm{f}} G_{\mathrm{SnO}_{2}}\right)$. In the present case, there are two chemical exchange reactions, i.e. $\left(\mathrm{Cu}_{2} \mathrm{O}+1 / 2 \mathrm{Sn}=1 / 2 \mathrm{SnO}_{2}+2 \mathrm{Cu}\right)$ and $(\mathrm{NiO}+1 /$ $2 \mathrm{Sn}=1 / 2 \mathrm{SnO}_{2}+\mathrm{Ni}$ ). It is assumed that the Gibbs energy change for the first reaction can be obtained as $\Delta_{\mathrm{r}} G_{\left(\mathrm{NiO} / \mathrm{SnO}_{2}\right)}=1 /$
$2 \Delta_{\mathrm{f}} G_{\mathrm{SnO}_{2}}-\Delta_{\mathrm{f}} G_{\mathrm{NiO}}$ and that for the second reaction as $\Delta_{\mathrm{r}} G_{\left(\mathrm{Cu}_{2} \mathrm{O} /\right.}$ $\left.\mathrm{SnO}_{2}\right)=1 / 2 \Delta_{\mathrm{f}} G_{\mathrm{SnO}_{2}}-\Delta_{\mathrm{f}} G_{\mathrm{Cu}_{2} \mathrm{O}}$. The Gibbs energies of formation for the oxides at $1073 \mathrm{~K}$ and $873 \mathrm{~K}$ were taken from ref. 37 and 38. Based on the obtained results, the calculated Gibbs energy change for the reactions is exothermic at both temperatures and equals $-93.3 \mathrm{~kJ} \mathrm{~mol}^{-1}$ and $-86.9 \mathrm{~kJ} \mathrm{~mol}^{-1}$ for $\Delta_{\mathrm{r}} G_{\left(\mathrm{Cu}_{2} \mathrm{O} / \mathrm{SnO}_{2}\right)}$, and $-38.2 \mathrm{~kJ} \mathrm{~mol}^{-1}$ and $-34.5 \mathrm{~kJ} \mathrm{~mol}^{-1}$ for $\Delta_{\mathrm{r}} G_{\left(\mathrm{NiO}_{\mathrm{SnO}}\right)}$ at $873 \mathrm{~K}$ and $1073 \mathrm{~K}$, respectively.

The amount of matter of the oxide shell can be expressed from its geometry as:

$$
n_{\beta} \cong A_{\mathrm{BET}} d \rho_{\beta} n_{\mathrm{Me}}^{0}
$$

where $\rho_{\beta}\left(\mathrm{g} \mathrm{m}^{-3}\right)$ is the density of the oxide shell. The quantities expressed by eqn (3) and (8) are equal. Consequently, the thickness of the oxide shell $(d)$ can be expressed as function of the mole fraction of the oxidized part of the nano-particle $(y)$, as:

$$
d \cong \frac{y}{A_{\mathrm{BET}} \rho_{\beta}} .
$$

Let us also mention that for $y=0$, eqn (4) becomes identical to eqn (1), being a reasonable boundary condition. Substituting eqn (5)-(7) and (9) into eqn (4), the excess nano heat effect can be calculated as function of $y$ for partly oxidized metallic nanoparticles.

The corresponding constants are given in Table 7. In this paper, the selection Sn was made (for the values in the last column of Table 8), as Sn has the highest affinity towards oxygen and the highest mole fraction in the liquid alloy among its components ( $\mathrm{Sn}, \mathrm{Cu}, \mathrm{Ag})$. The results calculated based on Table 8 are compared with experimental data in Fig. 11 and 12.

As follows from Fig. 11 and 12, the experimental results can be reproduced with $y=0.24 \pm 0.02$ for $\mathrm{Cu}$-nanoparticles and with $y=0.039 \pm 0.004$ for Ni-nanoparticles. These values are in qualitative agreement with Fig. 7-9. Thus, our new extended model is able to describe the nano heat effect for the dissolution of partly oxidized nano-particles.

\section{Experimental}

The heat effects of small additions of $\mathrm{Cu}$ and $\mathrm{Ni}$ to the liquid SAC387 alloy were investigated by a drop calorimetric 
Table 5 Enthalpies of mixing data for the addition of nano $\mathrm{Cu}$ into the liquid Sn-4.1Ag-1.3Cu alloy; standard states: pure liquid metals

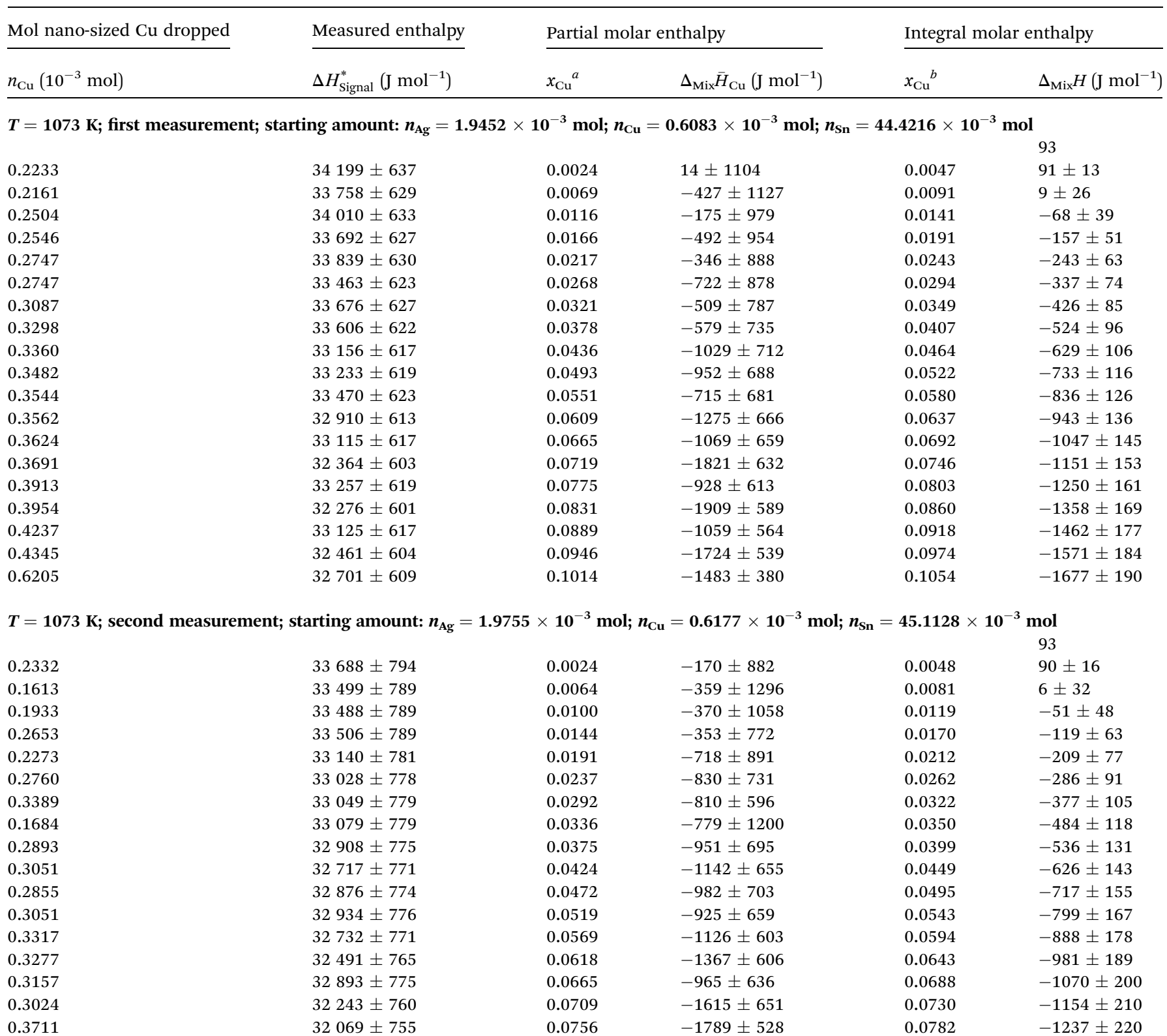

$T=873 \mathrm{~K}$; first measurement; starting amount: $n_{\mathrm{Ag}}=1.8702 \times 10^{-3} \mathrm{~mol} ; n_{\mathrm{Cu}}=0.5848 \times 10^{-3} \mathrm{~mol} ; n_{\mathrm{Sn}}=42.7094 \times 10^{-3} \mathrm{~mol}$ 
Table 5 (Contd.)

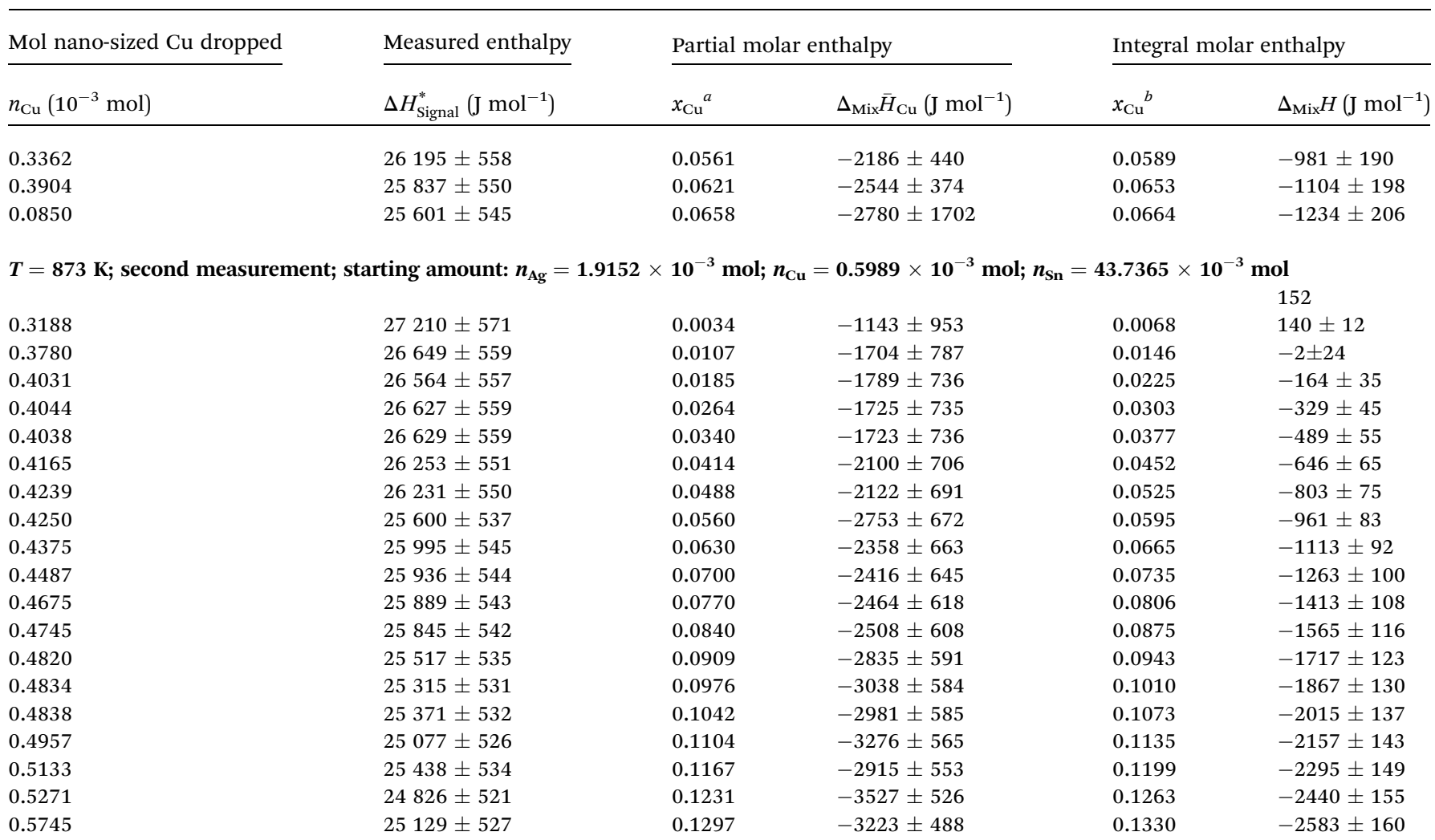

${ }^{a}$ Average of $x_{\mathrm{Cu}}$ before and after drop. ${ }^{b}$ Per mole of the mixture.

method. The measurements were carried out using a Calvettype twin microcalorimeter system under high purity $\mathrm{Ar}$ (99.9999\%) flow (approximately $20-30 \mathrm{ml} \mathrm{min}^{-1}$ ). The apparatus consists of two thermopiles containing more than 200 thermocouples, a commercial wire wound resistance furnace (HTC-1000, SETARAM, Lyon, France) and a self-made automatic drop device for up to 30 drops. The SAC387 alloy was placed in a BN crucible. The time interval between individual drops was $40 \mathrm{~min}$, and the acquisition interval of the heat flow was $0.5 \mathrm{~s}$. The calorimeter was calibrated by five drops of standard $\alpha-\mathrm{Al}_{2} \mathrm{O}_{3}$ provided by NIST (National Institute of Standards and Technology, Gaithersburg, MD) at the end of the drop series of each separate measurement. The microcalorimeter and the mechanical sampler were controlled through a self-provided software using the graphical programming environment LabVIEW. The obtained signals from the thermocouples were recorded and evaluated using the commercial $\mathrm{HiQ}^{\odot}$ software. The microcalorimeter was described in detail elsewhere. ${ }^{42}$

In general, the measured enthalpy (integrated heat flow at constant pressure) for bulk materials is equal to:

$$
\begin{aligned}
\left(\Delta H_{\text {Signal }}\right)_{\text {bulk }} & =n_{\mathrm{i}}\left(\Delta H_{\text {Signal }}^{*}\right)_{\text {bulk }} \\
& =n_{\mathrm{i}}\left(H_{\mathrm{m}, \mathrm{i}, \mathrm{T}_{M}}-H_{\mathrm{m}, \mathrm{i}, \mathrm{T}_{D}}\right)+\Delta H_{\text {Reaction }},
\end{aligned}
$$

where $n_{\mathrm{i}}$ is the number of moles of the added element i, $\Delta H_{\text {Signal }}^{*}$ is the measured enthalpy in $\mathrm{J} \mathrm{mol}^{-1}, H_{\mathrm{m}}$ denotes molar enthalpies, $T_{\mathrm{D}}$ is the drop temperature, and $T_{\mathrm{M}}$ is the calorimeter temperature for the respective measurement in Kelvin. The molar enthalpy difference $\left(H_{\mathrm{m}, \mathrm{i}, T_{\mathrm{M}}}-H_{\mathrm{m}, \mathrm{i}, T_{\mathrm{D}}}\right)$ was calculated using the SGTE data for pure elements. ${ }^{43}$

However, in the case of nanosized additions one must also take into account the additional heat effect caused by the excess (surface) enthalpy of the metal nanoparticles. Thus, eqn (10) for the addition in the nanosized form can be rewritten $\mathrm{as}^{\mathbf{1 9}}$ :

$$
\begin{aligned}
\left(\Delta H_{\text {Signal }}\right)_{\text {nano }} & =n_{\mathrm{i}}\left[\left(\Delta H_{\text {Signal }}^{*}\right)_{\text {bulk }}+\Delta H_{\mathrm{i}, \text { nano }}^{\mathrm{ex}}\right] \\
& =n_{\mathrm{i}}\left(H_{\mathrm{m}, \mathrm{i}, \mathrm{T}_{M}}-H_{\mathrm{m}, \mathrm{i}, \mathrm{T}_{D}}\right)+\Delta H_{\text {Reaction }}+n_{\mathrm{i}} \Delta H_{\mathrm{i}, \text { nano }}^{\mathrm{ex}}
\end{aligned}
$$

where $\Delta H_{\mathrm{i} \text {,nano }}^{\mathrm{ex}}$ is the excess enthalpy connected with the replacement of bulk material by nano-particles in $\mathrm{J} \mathrm{mol}^{-1}$. Therefore, in order to find the heat effect caused by the additions of material in nanosized form we must know the heat effect caused by the addition of the same material in bulk form.

Furthermore, due to the rather small masses of added component i, partial enthalpies can be calculated by:

$$
\Delta_{\mathrm{Mix}} \bar{H}_{\mathrm{i}} \approx \frac{\Delta H_{\text {Reaction }}}{n_{\mathrm{i}}} .
$$

The integral molar enthalpy of mixing, $\Delta_{\mathrm{Mix}} H$, was calculated by summing the respective reaction enthalpies and dividing by 
Table 6 Enthalpies of mixing data for the addition of nano Ni into the liquid Sn-4.1Ag-1.3Cu alloy; standard states: pure liquid metals

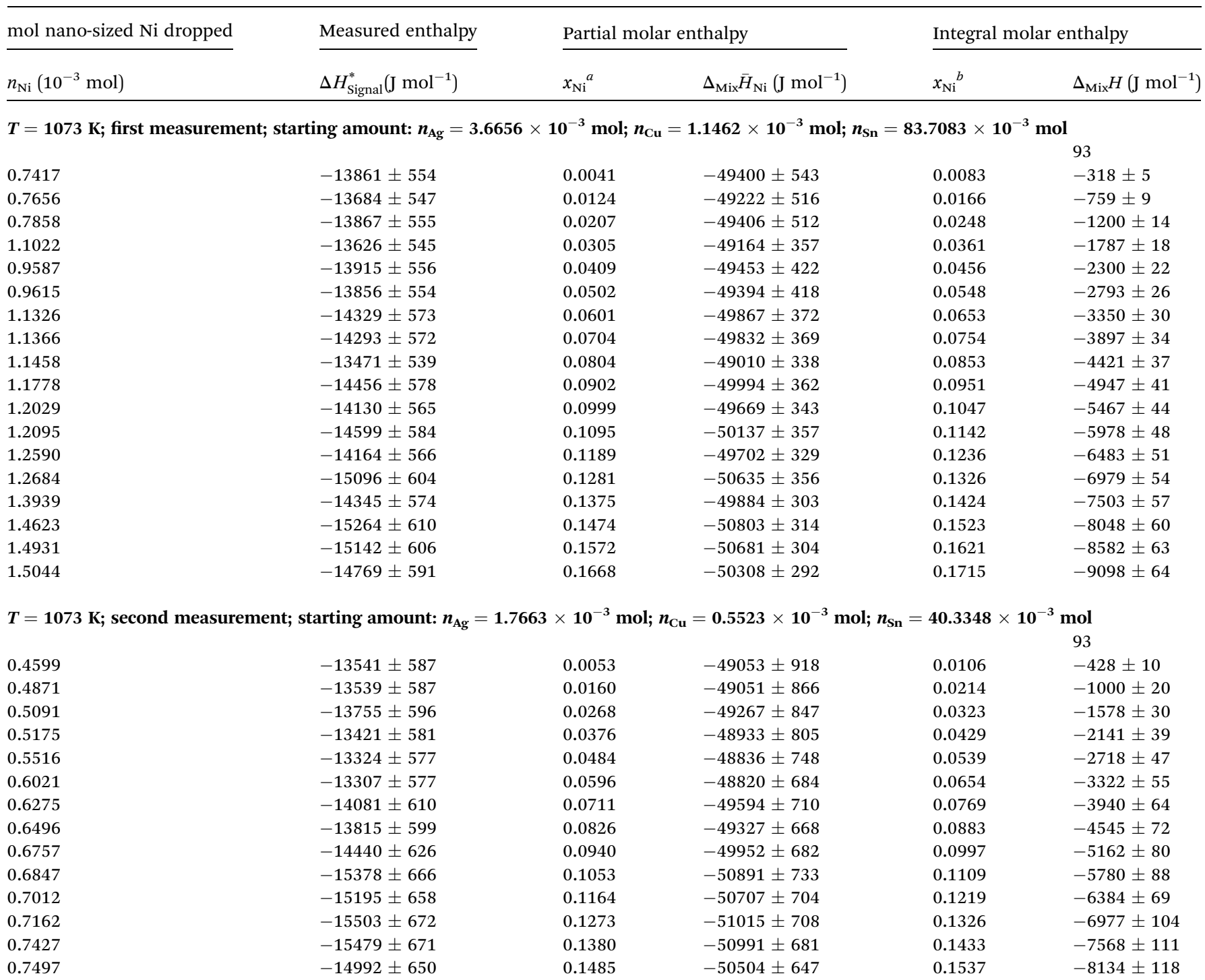

$T=873 \mathrm{~K}$; first measurement; starting amount: $n_{\mathrm{Ag}}=1.9944 \times 10^{-3} \mathrm{~mol} ; n_{\mathrm{Cu}}=0.6236 \times 10^{-3} \mathrm{~mol} ; n_{\mathrm{Sn}}=45.5455 \times 10^{-3} \mathrm{~mol}$

\begin{tabular}{|c|c|c|c|c|c|}
\hline & & & & & 152 \\
\hline 0.5701 & $-21187 \pm 669$ & 0.0058 & $-51159 \pm 991$ & 0.0116 & $-447 \pm 12$ \\
\hline 0.5162 & $-21731 \pm 687$ & 0.0167 & $-51703 \pm 1128$ & 0.0218 & $-1014 \pm 24$ \\
\hline 0.5665 & $-21908 \pm 692$ & 0.0272 & $-51880 \pm 1038$ & 0.0327 & $-1612 \pm 36$ \\
\hline 0.8113 & $-22802 \pm 720$ & 0.0401 & $-52774 \pm 759$ & 0.0476 & $-2441 \pm 48$ \\
\hline 0.8229 & $-22080 \pm 698$ & 0.0549 & $-52052 \pm 721$ & 0.0621 & $-3248 \pm 59$ \\
\hline 1.0979 & $-22729 \pm 718$ & 0.0714 & $-52701 \pm 559$ & 0.0807 & $-4279 \pm 69$ \\
\hline 0.6052 & $-23010 \pm 727$ & 0.0856 & $-52981 \pm 1029$ & 0.0905 & $-4860 \pm 80$ \\
\hline 0.2324 & $-22454 \pm 709$ & 0.0922 & $-52426 \pm 2604$ & 0.0939 & $-5075 \pm 91$ \\
\hline $\boldsymbol{T}=\mathbf{8 7 3}$ & rting amount: $n$ & $10^{-3} \mathrm{~m}$ & $0.5751 \times 10^{-3}$ & 41.9986 & \\
\hline & & & & & 152 \\
\hline 0.2662 & $-21613 \pm 474$ & 0.0030 & $-51585 \pm 1005$ & 0.0059 & $-157 \pm 9$ \\
\hline 0.2395 & $-21910 \pm 481$ & 0.0086 & $-51882 \pm 1135$ & 0.0112 & $-450 \pm 19$ \\
\hline 0.4425 & $-22942 \pm 484$ & 0.0159 & $-52014 \pm 619$ & 0.0207 & $-962 \pm 28$ \\
\hline 0.3227 & $-22008 \pm 483$ & 0.0240 & $-51980 \pm 847$ & 0.0273 & $-1341 \pm 37$ \\
\hline 0.5358 & $-22191 \pm 487$ & 0.0327 & $-52163 \pm 515$ & 0.0382 & $-1931 \pm 46$ \\
\hline 0.7365 & $-22375 \pm 491$ & 0.0454 & $-52347 \pm 378$ & 0.0526 & $-2723 \pm 54$ \\
\hline 0.5059 & $-21987 \pm 483$ & 0.0573 & $-51959 \pm 539$ & 0.0620 & $-3261 \pm 62$ \\
\hline 0.6155 & $-22840 \pm 501$ & 0.0675 & $-52811 \pm 464$ & 0.0731 & $-3881 \pm 69$ \\
\hline 0.2582 & $-22827 \pm 501$ & 0.0753 & $-52799 \pm 1105$ & 0.0775 & $-4152 \pm 78$ \\
\hline
\end{tabular}

${ }^{a}$ Average of $x_{\mathrm{Ni}}$ before and after drop. ${ }^{b}$ Per mole of the mixture. 


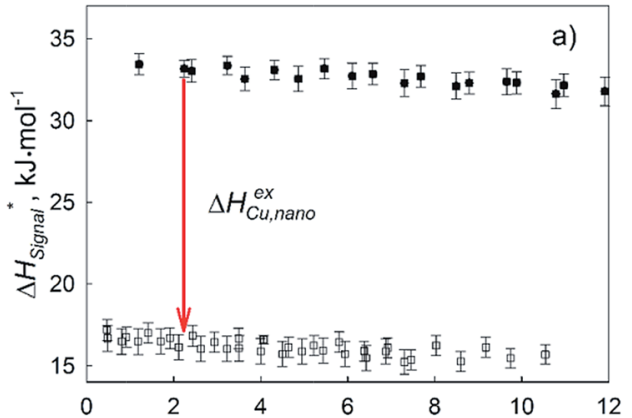

$\mathrm{Sn}-4.1 \mathrm{Ag}-1.3 \mathrm{Cu} \quad$ at. $\% \mathrm{Cu}$ (additional $\mathrm{Cu}$ )

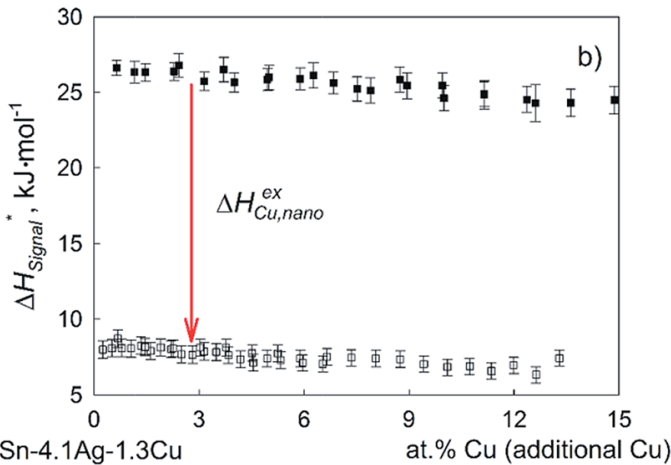

Fig. 5 Concentration dependencies of the measured enthalpy effect for $(\mathrm{Sn}-4.1 \mathrm{Ag}-1.3 \mathrm{Cu})_{100-x} \mathrm{Cu}_{x}$ at $1073 \mathrm{~K}$ (a) and $873 \mathrm{~K}$ (b) ( $\mathbf{\square}$ - for additions of bulk $\mathrm{Cu}$; $\square-$ for additions of nanosized $\mathrm{Cu}$ ).
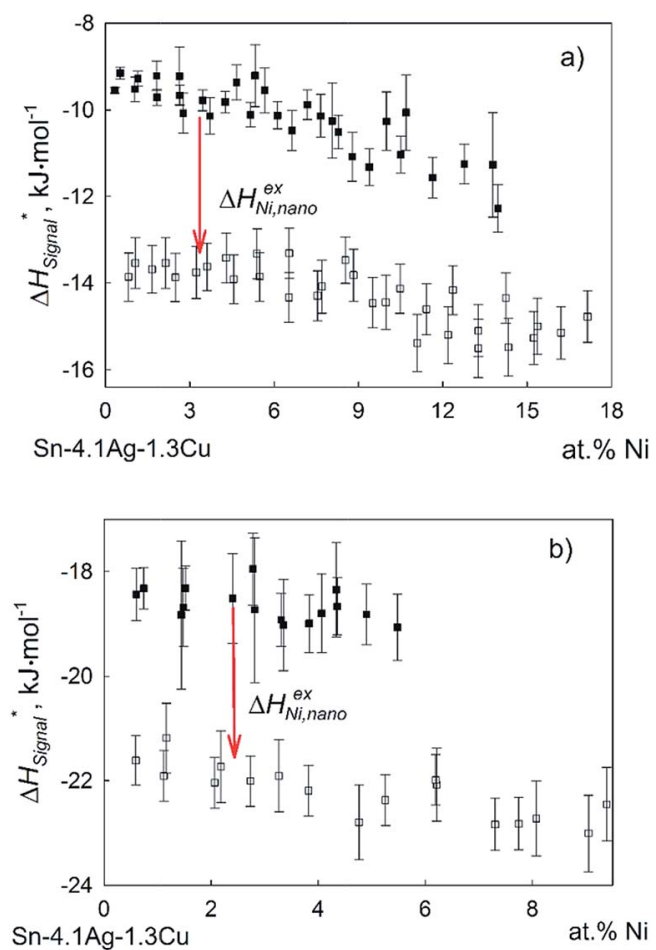

Fig. 6 Concentration dependencies of the measured enthalpy effect for $(\mathrm{Sn}-4.1 \mathrm{Ag}-1.3 \mathrm{Cu})_{100-x} \mathrm{Ni}_{x}$ at $1073 \mathrm{~K}$ (a) and $873 \mathrm{~K}$ (b) ( $\mathbf{\square}$ - for additions of bulk Ni; $\square-$ for additions of nanosized $\mathrm{Ni}$ ).
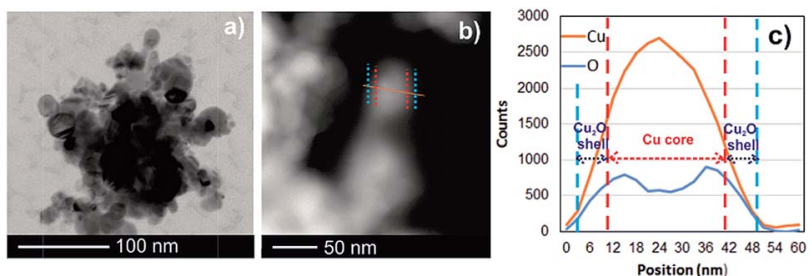

Fig. 7 TEM bright field image (a) and HAADF STEM image (b) with corresponding EDX linescan (c) of Cu NPs.
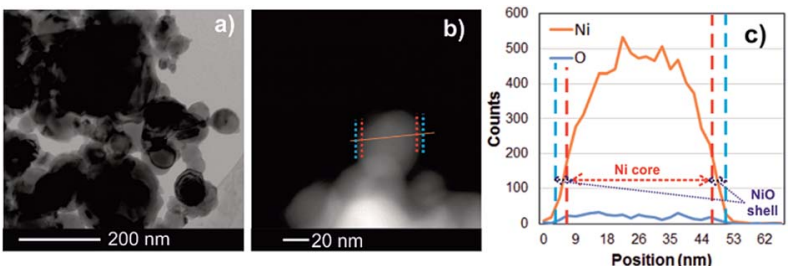

Fig. 8 TEM bright field image (a) and HAADF STEM image (b) with corresponding EDX linescan (c) of Ni NPS.

the total molar amount of substance, where $n_{\mathrm{j}}$ stands for the molar amount of substance which was already present in the crucible:

$$
\Delta_{\mathrm{Mix}} H=\frac{\sum \Delta H_{\text {Reaction }}}{n_{\mathrm{j}}+\sum n_{\mathrm{i}}} .
$$

Prior to the measurements, the SAC387 alloy was prepared from Sn ingot (99.998\% metallic purity), Ag shot (99.999\% metallic purity) and $\mathrm{Cu}$ rods (99.9\% metallic purity, all from Alfa Aesar, Karlsruhe, Germany) without further purification. The samples with a total mass between 5 and $10 \mathrm{~g}$ were sealed in evacuated quartz glass ampoules and kept in a muffle furnace for 2 weeks at $1173 \mathrm{~K}$. The mass loss of the ingots was less than $0.1 \mathrm{mg}$.

The measurements were performed by dropping pure $\mathrm{Ni}$ or $\mathrm{Cu}$, both in bulk and nanosized form. Ni pieces were obtained from Advent (99.99\%; Oxford, UK), Ni and $\mathrm{Cu}$ nanopowders from IoLiTec Nanomaterials (Heilbronn, Germany). To avoid severe oxidation, all operations with nano-Ni and nano-Cu were
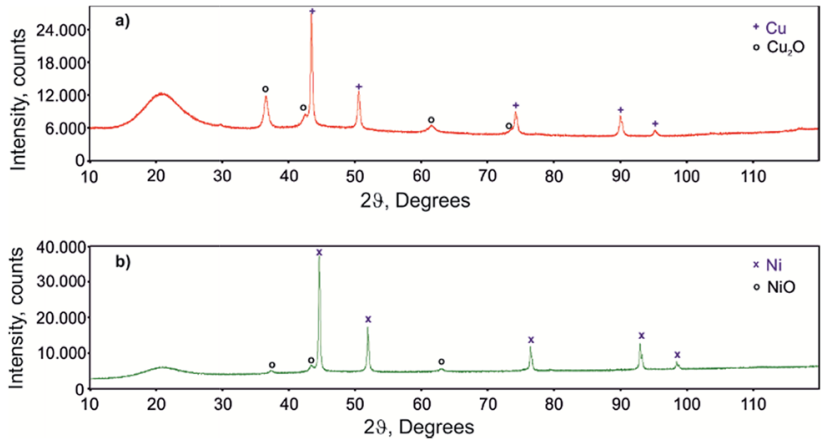

Fig. 9 XRD patterns of $\mathrm{Cu}(\mathrm{a})$ and Ni NPs (b) 

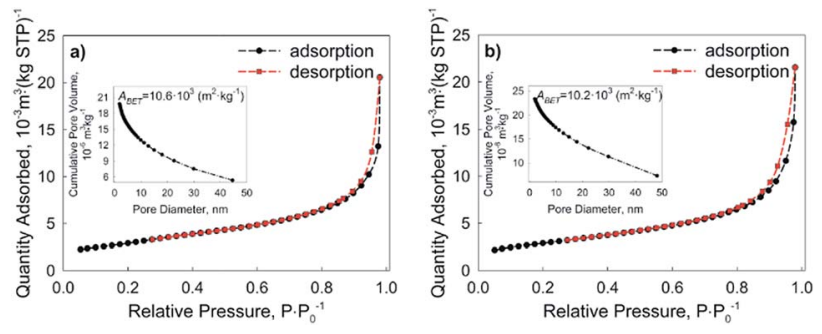

Fig. 10 BET isotherm and $\mathrm{BJH}$ pore size distribution of $\mathrm{Cu}(\mathrm{a})$ and $\mathrm{Ni}$ NPs (b).

performed in a glovebox (M. Braun, LabMaster 130) under Ar atmosphere ( $\mathrm{Ar} 5.0 ; \mathrm{O}_{2}$ and $\mathrm{H}_{2} \mathrm{O}<5$ ppm each). The calorimetric measurements using the metal nanopowders were carried out similar to our previous thermodynamic investigations of nanoCo additions to liquid SAC387 alloys. ${ }^{19}$ the $\mathrm{Ni}$ and $\mathrm{Cu}$ nanoparticles were first packed into a SAC387 foil. The employed foil was produced from the same ingot using a foil rolling mill; it had a thickness of about $50 \mu \mathrm{m}$. The sample holders of the auto sampling device were loaded with nanopowder samples inside the glovebox and closed in a box, which was only taken out just before the measurement to be transported to the calorimeter. The calorimetric measurements with the packed nanoparticles were started with five drops of SAC387 foil pieces in order to determine and, subsequently, subtract the heat effect of the SAC387 foil from the obtained measured enthalpy. A few measurements with bulk $\mathrm{Cu}$ and $\mathrm{Ni}$, packed into the SAC387 foil, were also carried out to prove the accuracy of this procedure.

Various factors must be considered when estimating the random and systematic errors in the measurements, i.e. the calorimeter construction, measuring method, calibration procedure, signal integration and "chemical errors". Uncertainties of the enthalpy values given in Tables 1-6 were estimated based on the propagation of errors, taking also into account the standard deviation of the calorimeter constant $s(k)$

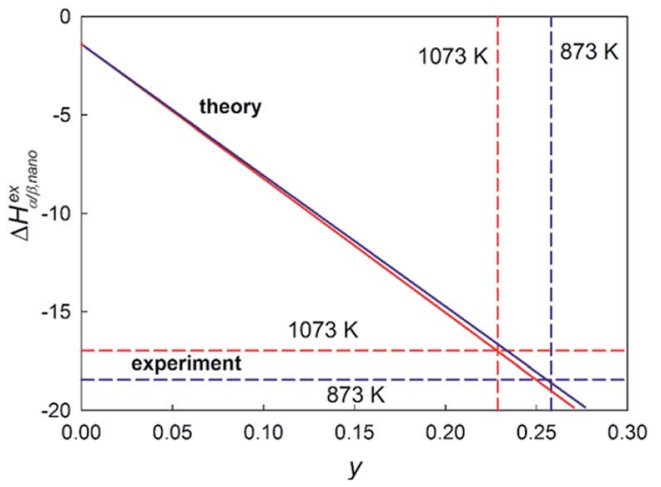

Fig. 11 Comparison of experimental data (dotted horizontal lines) with theoretical values (bold lines) at two temperatures for the dependence of the excess nano enthalpy effect on the ratio of oxidation of the $\mathrm{Cu}$ nanoparticles. Calculated by eqn (5)-(7) and (9) and parameters of Table 8

which was evaluated by five drops of alumina for each run. The uncertainty of the partial enthalpy of mixing for each drop was calculated based on the uncertainties of peak areas of each drop, $A_{\mathrm{i}}$, of the amount of added component, $n_{\mathrm{i}}$, and $s(k)$; the error of the integrated enthalpy of mixing was taken summarizing the errors of the single drops throughout the final composition. A similar procedure of calculation of the uncertainties of the enthalpy values was employed previously in ref. 44 and 45.

The phase composition and the microstructure of the samples were examined after the calorimetric measurements by powder X-ray diffraction (XRD; Bruker D8 Advance X-ray diffractometer) and scanning electron microscopy (SEM; Zeiss Supra 55 ESEM). The XRD analysis was carried out at ambient temperature using Ni-filtered $\mathrm{Cu} \mathrm{K} \alpha$ radiation (accelerating voltage $40 \mathrm{kV}$, electron current $40 \mathrm{~mA}$ ). The nanopowders were fixed onto the sample holder using pre-dried petroleum jelly in the Ar-filled glovebox. Rietveld refinement of XRD patterns was performed with the Topas 3 software provided by Bruker AXS.

Table 7 Calculated and measured nano-effects $\left(\Delta H_{\mathrm{i}, \text { nano, }}^{\mathrm{ex}} \mathrm{kJ} \mathrm{mol}^{-1}\right)$ without considering the influence of the oxide shell on the nano-particles

\begin{tabular}{llllll}
\hline Metal & $A_{\mathrm{BET}}\left(\mathrm{m}^{2} \mathrm{~g}^{-1}\right)$ & $\begin{array}{l}M \\
\left(\mathrm{~g} \mathrm{~mol}^{-1}\right)\end{array}$ & $\left.\left.\sigma_{\mathrm{sg}, \mathrm{H}, T_{\mathrm{D}}}\right) \mathrm{J} \mathrm{m}^{-2}\right)^{35}$ & $\Delta H_{\mathrm{i}, \text { nano }}^{\text {ex }}$ eqn $(1)$ & $-1.3 \pm 0.2$ \\
$\mathrm{Cu}$ & $10.6 \pm 0.4$ & 63.55 & $1.93 \pm 0.19$ & $-1.4 \pm 0.2$ & $-3.5 \pm 0.3$
\end{tabular}

Table 8 Parameters to calculate the excess nano heat effect $\Delta H_{\mathrm{i}, \text { nano }}^{\text {exp }}\left(\mathrm{kJ} \mathrm{mol}^{-1}\right)$ by eqn (4) $-(7)$ and $(9)^{a}$

\begin{tabular}{|c|c|c|c|c|c|c|c|c|c|c|c|}
\hline Metal & $\begin{array}{l}A_{\mathrm{BET}} \\
\left(\mathrm{m}^{2} \mathrm{~g}^{-1}\right)\end{array}$ & $\begin{array}{l}M_{\alpha} \\
\left(\mathrm{g} \mathrm{mol}^{-1}\right)\end{array}$ & $\beta_{x}$ & $\begin{array}{l}M \\
\left(\mathrm{~g} \mathrm{~mol}^{-1}\right)\end{array}$ & $\begin{array}{l}\rho_{\beta} \\
\left(\mathrm{g} \mathrm{cm}^{-3}\right)\end{array}$ & $\begin{array}{l}\sigma_{\alpha, \mathrm{H}, \mathrm{T}_{\mathrm{D}}} \\
\left(\mathrm{J} \mathrm{m}^{-2}\right)\end{array}$ & $\begin{array}{l}\sigma_{\beta, \mathrm{H}, T_{\mathrm{D}}} \\
\left(\mathrm{J} \mathrm{m}^{-2}\right)\end{array}$ & $\begin{array}{l}\sigma_{\alpha / \beta, \mathrm{H}, T_{\mathrm{D}}} \\
\left(\mathrm{J} \mathrm{m}^{-2}\right)\end{array}$ & $T(\mathrm{~K})$ & $\begin{array}{l}\Delta H_{\mathrm{C}_{\mathrm{p}}} \\
\left(\mathrm{kJ} \mathrm{mol}^{-1}\right)\end{array}$ & $\begin{array}{l}\Delta_{\mathrm{r}} H^{0} \\
\left(\mathrm{~kJ} \mathrm{~mol}{ }^{-1}\right)\end{array}$ \\
\hline $\mathrm{Cu}$ & 10.6 & 63.55 & 0.5 & 71.55 & 6.0 & 1.93 & 0.7 & 1.93 & 873 & 6.00 & -71.05 \\
\hline $\mathrm{Ni}$ & 10.2 & 58.69 & 1 & 74.69 & 7.45 & 2.36 & 0.9 & 2.36 & 873 & 13.96 & -61.84 \\
\hline $\mathrm{Ni}$ & 10.2 & 58.69 & 1 & 74.69 & 7.45 & 2.36 & 0.9 & 2.36 & 1073 & 18.208 & -64.33 \\
\hline
\end{tabular}

${ }^{a}$ Density is from ref. 39, interfacial energies are from ref. 35 and 40, and enthalpy data are from ref. 41. 


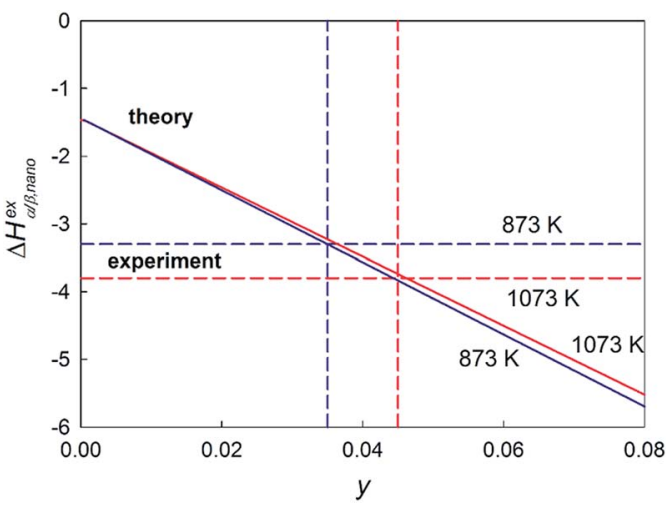

Fig. 12 Comparison of experimental data (dotted horizontal lines) with theoretical values (bold lines) at two temperatures for the dependence of the excess nano enthalpy effect on the ratio of oxidation of the Ni nanoparticles. Calculated by eqn (4)-(7) and (9) and parameters of Table 8 .

The energy-dispersive X-ray (EDX) detector signal for SEM analysis was calibrated using pure elements as standard materials and Co for the energy calibration.

The $\mathrm{Ni}$ and $\mathrm{Cu}$ nanoparticles were characterized by XRD analysis (XRD; Bruker D8 Advance X-ray diffractometer) and transmission electron microscopy (TEM; analytical TECNAI F20 field emission TEM). A silicon single crystal sample holder with a matching polymer (polycarbonate) cap was used in order to avoid a possible oxidation of NPs. The EDX mapping of NPs was performed with an energy-dispersive X-ray detector (EDAX TEAM Apollo XLTW SDD).

The surface area of the nanopowders was estimated using the BET technique, whereby $\mathrm{N}_{2}$ adsorption-desorption isotherms of the nanopowders were analyzed using a TriStar II 3020 instrument (Micromeritics). This method is based on a theory developed by S. Brunauer, P. Emmett and E. Teller ${ }^{46}$ where the name of the theory was taken from the first letter of each author's surnames. According to this method, the surface area of a known mass of a sample was determined by monitoring the mass change by adsorption of nitrogen over time, which is widely used due to its availability in high purity and its strong interaction with most solids. The data collected during the measurement are shown in the form of a BET isotherm, which plots the quantity of gas adsorbed as a function of the relative pressure.

\section{Conclusions}

The presented experimental results show clearly that an extra exothermic heat effect (nano-heat effect) is observed when bulk pieces are replaced by nano-particles in drop calorimetric measurements. First of all, this is due to the loss of the large surface area of the nano-particles upon their dissolution. However, when the nano-particles are covered with a surface oxide shell, resulting in an exothermic chemical reaction with the solvent (a liquid alloy in the present case), the measured nano-effect can become even more exothermic, especially if the reaction enthalpy is strongly negative. This effect has been examined here on the example of the core/shell $\mathrm{Cu} / \mathrm{Cu}_{2} \mathrm{O}$ and $\mathrm{Ni} / \mathrm{NiO}$ nano-particles dropped into Sn-rich liquid alloys.

\section{Conflicts of interest}

There are no conflicts to declare.

\section{Acknowledgements}

This work was supported by the Austrian Science Fund (FWF) [grant numbers P 26304 and P 27049]. The authors want to acknowledge the help of Prof. M. Zehetbauer and Prof. E. Schafler from the Faculty of Physics, University of Vienna, with the Sn-4.1Ag-1.3Cu foil preparation, Ing. C. Mitterer from the Faculty of Chemistry, University of Vienna, with BET analysis and Dr St. Puchegger from the Faculty of Physics, University of Vienna, with the SEM studies. TEM analysis was performed using the facilities at the University Service Center for Transmission Electron Microscopy at the Vienna University of Technology. The work by G.K. was supported by project GINOP 2.3.2 $-15-2016-00027$ financed in the framework of the Széchenyplan supported by the European Union.

\section{References}

1 M. Zhang, M. Y. Efremov, F. Schiettekatte, E. A. Olson, A. T. Kwan, S. L. Lai, T. Wisleder, J. E. Greene and L. H. Allen, Phys. Rev. B, 2000, 62, 10548-10557.

2 S. Y. Xiong, W. H. Qi, Y. J. Cheng, B. Y. Huang, M. P. Wang and Y. J. Li, Phys. Chem. Chem. Phys., 2011, 13, 10652-10660.

3 R. Ferrando, Structure and properties of nanoalloys, Elsevier, Amsterdam, 2016, vol 10.

4 Y. Hua, K. Chandra, D. H. M. Dam, G. P. Wiederrecht and T. W. Odom, J. Phys. Chem. Lett., 2015, 6, 4904-4908.

5 K. S. Lee and M. A. El-Sayed, J. Phys. Chem. B, 2006, 110, 19220-19225.

6 N. Dai, L. Zhang, Z. Wang, X. Wang, J. Zhang, H. Gong, H.-B. Han and Y. Han, J. Phys. Chem. C, 2017, 121, 1235812364.

7 I. Papagiannouli, P. Aloukos, D. Rioux, M. Meunier and S. Couris, J. Phys. Chem. C, 2015, 119, 6861-6872.

8 S. W. Baek, G. Park, J. Noh, C. Cho, C. H. Lee, M. K. Seo, H. Song and J. Y. Lee, ACS Nano, 2014, 8, 3302-3312.

9 E. Hao, G. C. Schatz and J. T. Hupp, J. Fluoresc., 2004, 14, 331-341.

10 W. H. Qi, Acc. Chem. Res., 2016, 49, 1587-1595.

11 J. Shen and Y. C. Chan, Microelectron. Reliab., 2009, 49, 223234.

12 L. Sun and L. Zhang, Adv. Mater. Sci. Eng., 2015, 2015, 639028.

13 E. E. M. Noor, A. Singh and T. C. Yap, Soldering Surf. Mount Technol., 2013, 25, 229-241.

14 A. Yakymovych, Y. Plevachuk, P. Svec, D. Janikovic, P. Sebo, N. Beronska, M. Nosko, L. Orovcik, A. Roshanghias and H. Ipser, J. Mater. Sci.: Mater. Electron., 2017, 28, 1096510973. 
15 M. N. Bashir, A. S. M. A. Haseeb, A. M. S. Rahman, M. A. Fazal and C. R. Kao, J. Mater. Sci., 2015, 50, 6748-6756. 16 A. K. Gain and Y. C. Chan, Intermetallics, 2012, 29, 48-55. 17 L. Zhang and K. N. Tu, Mater. Sci. Eng., R, 2014, 82, 1-32.

18 S. L. Tay, A. S. M. A. Haseeb, M. R. Johan, P. R. Munroe and M. Z. Quadir, Intermetallics, 2013, 33, 8-15.

19 A. Yakymoyych, G. Kaptay, A. Roshanghias, H. Flandorfer and H. Ipser, J. Phys. Chem. C, 2016, 120, 1881-1890.

20 A. Yakymoyych, Y. Plevachuk, V. Sklyarchuk, B. Sokoliuk, T. Galya and H. Ipser, J. Phase Equilib. Diffus., 2017, 38, 217-222.

21 A. Yakymovych, S. Mudry, I. Shtablavyi and H. Ipser, Mater. Chem. Phys., 2016, 181, 470-475.

22 A. T. Tan, A. W. Tan and F. Yusof, Sci. Technol. Adv. Mater., $2015,16$.

23 H. Flandorfer, C. Luef and U. Saeed, J. Non-Cryst. Solids, 2008, 354, 2953-2972.

24 C. Luef, H. Flandorfer and H. Ipser, Z. Metallkd., 2004, 95, 151-163.

25 G. Kaptay, Metall. Mater. Trans. A, 2012, 43, 531-543.

26 U. Saeed, H. Flandorfer and H. Ipser, J. Mater. Res., 2007, 22, 3218-3225.

27 S. W. Chen and C. A. Chang, J. Electron. Mater., 2004, 33, 1071-1079.

28 C. Schmetterer, M. Rodriguez-Hortala and H. Flandorfer, J. Phase Equilib. Diffus., 2014, 35, 429-433.

29 S. Furtauer, D. Li, D. Cupid and H. Flandorfer, Intermetallics, 2013, 34, 142-147.
30 W. Wang, Z. G. Liao, Y. Wang, X. A. Wu, F. Y. Qu and X. Zhang, Cryst. Res. Technol., 2011, 46, 300-304.

31 P. E. Tomaszewski, Phase Transitions, 1992, 38, 127-220.

32 R. Vallee, M. Wautelet, J. P. Dauchot and M. Hecq, Nanotechnology, 2001, 12, 68-74.

33 G. Kaptay, J. Nanosci. Nanotechnol., 2012, 12, 2625-2633.

34 G. Kaptay, RSC Adv., 2017, 7, 41241-41253.

35 L. Z. Mezey and J. Giber, Jpn. J. Appl. Phys., Part 1, 1982, 21, 1569-1571.

36 G. Kaptay, J. Mater. Sci., 2012, 47, 8320-8335.

37 R. D. Holmes, H. S. C. O'Neill and R. J. Arculus, Geochim. Cosmochim. Acta, 1986, 50, 2439-2452.

38 G. Petot-Ervas, R. Farhi and C. Petot, J. Chem. Thermodyn., 1975, 7, 1131-1136.

39 G. V. Samsonov, Physico-chemical properties of oxides, Metallurgia, Moscow, 1978.

40 G. Kaptay, E. Bader and L. Bolyan, Mater. Sci. Forum, 2000, 329-3, 151-156.

41 I. Barin and F. Sauert, Thermochemical properties of pure substances, Wiley-VCH, New York, 1993.

42 H. Flandorfer, F. Gehringer and E. Hayer, Thermochim. Acta, 2002, 382, 77-87.

43 A. T. Dinsdale, CALPHAD, 1991, 15, 317-425.

44 A. Yakymovych, S. Furtauer, H. Flandorfer and H. Ipser, Monatsh. Chem., 2014, 145, 1697-1706.

45 A. Yakymovych, S. Furtauer, A. Elmahfoudi, H. Ipser and H. Flandorfer, J. Chem. Thermodyn., 2014, 74, 269-285.

46 S. Brunauer, P. H. Emmett and E. Teller, J. Am. Chem. Soc., 1938, 60, 309-319. 